\title{
Analysis of Bacterial Communities on North Sea Macroalgae and Characterization of the Isolated Planctomycetes Adhaeretor mobilis gen. nov., sp. nov., Roseimaritima multifibrata sp. nov., Rosistilla ulvae sp. nov. and Rubripirellula lacrimiformis sp. nov.
}

\author{
Sandra Wiegand ${ }^{1,2,+}{ }^{\dagger}$ Patrick Rast ${ }^{3,+}{ }^{+}$Nicolai Kallscheuer ${ }^{1,4} \oplus$, Mareike Jogler ${ }^{5}$, Anja Heuer ${ }^{3}$, \\ Christian Boedeker ${ }^{3}$, Olga Jeske ${ }^{3}$, Timo Kohn ${ }^{1}$, John Vollmers ${ }^{2}$, Anne-Kristin Kaster ${ }^{2}$, Christian Quast ${ }^{6}$, \\ Frank Oliver Glöckner ${ }^{7}$, Manfred Rohde ${ }^{8}$ and Christian Jogler ${ }^{1,5, *}$
}

\section{check for} updates

Citation: Wiegand, S.; Rast, P.; Kallscheuer, N.; Jogler, M.; Heuer, A.; Boedeker, C.; Jeske, O.; Kohn, T.; Vollmers, J.; Kaster, A.-K.; et al. Analysis of Bacterial Communities on North Sea Macroalgae and Characterization of the Isolated Planctomycetes Adhaeretor mobilis gen. nov., sp. nov., Roseimaritima multifibrata sp. nov., Rosistilla ulvae sp. nov. and Rubripirellula lacrimiformis $\mathrm{sp}$. nov. Microorganisms 2021, 9, 1494. https://doi.org/10.3390/ microorganisms 9071494

Academic Editors: Lise Øvreås, Olga Maria Lage and Damien P. Devos

Received: 1 June 2021

Accepted: 8 July 2021

Published: 13 July 2021

Publisher's Note: MDPI stays neutral with regard to jurisdictional claims in published maps and institutional affiliations.

Copyright: (c) 2021 by the authors. Licensee MDPI, Basel, Switzerland. This article is an open access article distributed under the terms and conditions of the Creative Commons Attribution (CC BY) license (https:/ / creativecommons.org/licenses/by/ $4.0 /)$.
1 Department of Microbiology, Radboud University, 6525 AJ Nijmegen, The Netherlands; sandra.wiegand@kit.edu (S.W.); n.kallscheuer@science.ru.nl (N.K.); ti.kohn@t-online.de (T.K.)

2 Institute for Biological Interfaces 5 (IBG-5), Karlsruhe Institute of Technology, 76131 Karlsruhe, Germany; john.vollmers@kit.edu (J.V.); anne-kristin.kaster@kit.edu (A.-K.K.)

3 Leibniz Institute DSMZ, 38124 Braunschweig, Germany; raspat88@gmail.com (P.R.); ast11@dsmz.de (A.H.); c.boedeker.dsmz@gmail.com (C.B.); olga.jeske@web.de (O.J.)

4 Institute of Bio- and Geosciences, Biotechnology (IBG-1), Forschungszentrum Jülich GmbH, 52428 Jülich, Germany

5 Department of Microbial Interactions, Institute of Microbiology, Friedrich-Schiller University, 07743 Jena, Germany; mareike@jogler.de

6 Max Planck Institute for Marine Microbiology, 28359 Bremen, Germany; c.quast@jacobs-university.de

7 Alfred Wegener Institute Bremerhaven, MARUM, University of Bremen, 28359 Bremen, Germany; frank.oliver.gloeckner@awi.de

8 Central Facility for Microscopy, Helmholtz Centre for Infection Research, 38124 Braunschweig, Germany; Manfred.Rohde@helmholtz-hzi.de

* Correspondence: christian.jogler@uni-jena.de; Tel.: +49-364-194-9301

+ Contributed equally.

Abstract: Planctomycetes are bacteria that were long thought to be unculturable, of low abundance, and therefore neglectable in the environment. This view changed in recent years, after it was shown that members of the phylum Planctomycetes can be abundant in many aquatic environments, e.g., in the epiphytic communities on macroalgae surfaces. Here, we analyzed three different macroalgae from the North Sea and show that Planctomycetes is the most abundant bacterial phylum on the alga Fucus sp., while it represents a minor fraction of the surface-associated bacterial community of Ulva sp. and Laminaria sp. Especially dominant within the phylum Planctomycetes were Blastopirellula sp., followed by Rhodopirellula sp., Rubripirellula sp., as well as other Pirellulaceae and Lacipirellulaceae, but also members of the OM190 lineage. Motivated by the observed abundance, we isolated four novel planctomycetal strains to expand the collection of species available as axenic cultures since access to different strains is a prerequisite to investigate the success of planctomycetes in marine environments. The isolated strains constitute four novel species belonging to one novel and three previously described genera in the order Pirellulales, class Planctomycetia, phylum Planctomycetes.

Keywords: budding bacteria; Pirellulaceae; Lacipirellulaceae; marine biofilms; epiphytic community; macroalgae; Fucus sp.; Ulva sp.; Laminaria sp.

\section{Introduction}

In aquatic environments, microorganisms either follow a planktonic lifestyle, floating or swimming in the water column, or switch to an attached state by forming biofilms on all kinds of natural or artificially introduced surfaces, e.g., steel and microplastics [1-3]. While biotic surfaces as such provide a source of organic matter, the same is also true for 
abiotic surfaces as soon as polar and hydrophobic materials start to accumulate on these submerged surfaces [3]. In general, marine biofilms are most often colonized by members of the marine Roseobacter clade (Alphaproteobacteria) as well as Alteromonadaceae, Vibrionaceae (both Gammaproteobacteria), and Bacteroidetes [3,4]. It is known that (seasonal) environmental dynamics, such as changes of temperature or salinity, but also stress factors, such as the presence of oxidants or metal ions, strongly influence epiphytic communities [5-8]. It was also shown that these communities can be very specific to their hosts $[9,10]$.

A large fraction of marine biotic surfaces is formed by macroalgae, a generic term for sessile Rhodophyta, Phaeophyta, and Chlorophyta (red, brown, and green algae, respectively). Bacterial biofilms and marine macroalgae have been described to have a mutualistic as well as an opportunistic relation, with microorganisms protecting the alga from foulinginducing organisms, enabling substrate exchange of, e.g., vitamin $\mathrm{B}_{12}$, fixing nitrogen, playing an important part in the algal morphology development, and influencing the release and settlement of algal spores, but also exploiting the rich repertoire of substrates on the algal surface [11-13]. Several studies on the composition of the various macroalgal epiphytic communities found Alphaproteobacteria, Gammaproteobacteria, and Bacteroidetes to often be the most dominant taxa within these communities, followed by-depending on the analyzed algae-Actinobacteria, Firmicutes, Verrucomicrobia, Deltaproteobacteria, and Planctomycetes [13-18]. Interestingly, Aquificae, Chlorobi, Dyctioglomi, Lentisphaerae, Tenericutes, and Gemmatimonadetes were only found on certain macroalgal groups [12].

Marine biofilms provide a rich source for hidden microbial diversity and functionalities, e.g., the synthesis of secondary metabolites [18]. The presence of members of the phylum Planctomycetes has been shown especially for Ulva sp., Chondrus sp., Fucus sp., and Laminaria sp. [19-23]. Usually, members of the class Planctomycetia were found to constitute the majority of the identified planctomycetes, followed by members of the OM190 lineage [19,21,22]. Nevertheless, the first two described planctomycetal isolates from macroalgae belong to the class Phycisphaerae [24-26]. In recent years, single-cell genomes [27] and axenic cultures from macroalgae were also obtained for the families Pirellulaceae [28-31], Lacipirellulaceae [32], Planctomycetaceae [33-35], and Isosphaeraceae [36].

Planctomycetes possess several traits that make them well-suited for the life in marine biofilms, for example the presence of a holdfast structure that facilitates surface colonization $[3,25]$. Species of the class Planctomycetia divide by budding, a feature they share with other frequent biofilm dwellers of the families Hyphomonadaceae and Rhodobacteraceae [25]. Despite the capability to quickly adapt to environmental changes [37], planctomycetes are described to be slow-growing organisms with generation times of several hours up to days, which makes them susceptible to being outgrown by other bacteria [25]. Thus, planctomycetes must apply other strategies to succeed, such as their big genomes that encode, e.g., a plethora of sulfatases enabling the degradation of complex sulfated polysaccharides found in the cell walls of various algae [38]. In addition, they possess many biosynthetic gene clusters that are potentially involved in the production of secondary metabolites [39], e.g., a novel group of small molecules that is responsible for altering the species composition of biofilms [40]. An additional advantage over the use of exoenzymes for degradation might also be their capability to accumulate complex carbohydrates such as dextran in their enlarged and invaginated periplasmic space [41]. Taken together, the recent findings point towards complex allelopathic interactions of planctomycetes with marine macroscopic phototrophs.

Here, we report the results of a $16 \mathrm{~S}$ rRNA gene amplicon-based cultivation-independent analysis of bacterial communities of algal biofilms and the surrounding waters, elucidating the diversity and abundance of members of the phylum Planctomycetes in biofilms of the three North Sea macroalgal specimens (Fucus sp., Ulva sp., and Laminaria sp.). Moreover, we describe the physiology, chemotaxonomy, morphology, cell biology, genomic features, and phylogeny of four novel planctomycetal isolates, representing one novel genus and three novel species within this phylum. 


\section{Materials and Methods}

\subsection{Sampling and Sample Preparation}

Algal material of Laminaria sp., Fucus sp., and Ulva sp. and samples from water surrounding each alga were collected in sterile $1 \mathrm{~L}$ bottles during low tide on the north shore of Helgoland Island, Germany on 5 June 2013 (exact sampling location $54.188^{\circ} \mathrm{N}$, $7.875^{\circ} \mathrm{E}$, water temperature $13{ }^{\circ} \mathrm{C}$ ). The samples were immediately transferred to the Biologische Anstalt Helgoland. The algae were stored in separated natural seawater tanks at $13{ }^{\circ} \mathrm{C}$ and water samples were stored at $4{ }^{\circ} \mathrm{C}$. All samples were transferred to the DSMZ, Braunschweig, Germany within $24 \mathrm{~h}$ and processed within $4 \mathrm{~h}$ after arrival. In the laboratory, $300 \mathrm{~mL}$ of the water samples were homogenized by gentle stirring and subjected to a two-step filtration process to separate aggregated/particle-attached and planktonic bacterial cells [42]. In the first step, the water was filtered through a borosilicate glass microfiber filter (Whatman GF/D, GE Healthcare, Dassel, Germany) with a pore size of $2.7 \mu \mathrm{m}$ to retain aggregated cells and marine particles. The same $300 \mathrm{~mL}$ of water was then filtered through a polycarbonate membrane filter (Isopore/Merck, Darmstadt, Germany) with a pore size of $0.22 \mu \mathrm{m}$ to obtain the fraction of planktonic microorganisms. Filters were stored at $-20^{\circ} \mathrm{C}$. Material of Laminaria sp., Fucus sp., and Ulva sp. was gently rinsed two times with filter-sterilized (Corning bottle top filters, Sigma-Aldrich, Schnelldorf, Germany) natural seawater to remove unattached bacteria. Biofilm suspensions were prepared by carefully scraping off algal biofilms into sterile natural seawater with single-use scalpels. Biofilm suspensions of all three algae were homogenized by vortexing, split into two equal volumes and stored at $-20^{\circ} \mathrm{C}$ until DNA extraction or at $4{ }^{\circ} \mathrm{C}$ until use in cultivation experiments (on the same day). Biofilms used for cultivation were supplemented with $20 \mathrm{mg} / \mathrm{mL}$ cycloheximide to inhibit the growth of fungi. Algal material was rinsed two times with sterile natural seawater and treated with $20 \mathrm{mg} / \mathrm{mL}$ cycloheximide dissolved in sterile natural seawater. Ten pieces of the collected algae with a diameter of $3 \mathrm{~cm}$ were sampled with a sterilized metal puncher and stored in sterile natural seawater until cultivation later that day. For each piece, five smaller pieces (diameter $0.5 \mathrm{~cm}$ ) directly adjacent to the larger pieces were gathered and directly fixed in $1.5 \%(v / v)$ formaldehyde solution for subsequent field emission scanning electron microscopy.

\subsection{Isolation and Cultivation of Novel Strains}

For bacterial cultivation, different media were prepared (Supplementary Table S1). All media contained $2.38 \mathrm{~g}$ / L HEPES (Serva, Heidelberg, Germany) as buffering agent, $20 \mathrm{~mL} / \mathrm{L}$ mineral salt solution, $250 \mathrm{~mL} / \mathrm{L}$ concentrated artificial seawater (ASW) and were adjusted to $\mathrm{pH} 8.0$ with $5 \mathrm{M} \mathrm{KOH}$. After sterilization by autoclaving, media were supplemented with $5 \mathrm{~mL} / \mathrm{L}$ double concentrated vitamin solution and $1 \mathrm{~mL} / \mathrm{L}$ trace element solution (for exact recipes of mineral salt, vitamin and trace element solution as well as ASW, see [39]. For the preparation of solid media, either $12 \mathrm{~g} / \mathrm{L}$ agar (BD Difco, Franklin Lakes, NJ, USA), washed three times with deionized water, or $8 \mathrm{~g} / \mathrm{L}$ gellan gum (Gelrite, Serva, Heidelberg, Germany) were autoclaved separately and added to the medium prior to pouring plates. For the initial isolation, 0,20 , or $100 \mathrm{mg} / \mathrm{L}$ cycloheximide were added to each medium to test the necessity for anti-fungal agents. In addition, media were also supplemented with $2000 \mathrm{mg} / \mathrm{L}$ carbenicillin or a mixture of $200 \mathrm{mg} / \mathrm{L}$ ampicillin and $1000 \mathrm{mg} / \mathrm{L}$ streptomycin to test the effectiveness of different antibiotic agents to selectively enrich planctomycetes (which show natural resistance to the used antibiotics). Initial isolation media also contained either $0.25 \mathrm{~g} / \mathrm{L}$ peptone (BD Difco), $0.25 \mathrm{~g} / \mathrm{L}$ yeast extract (BD Difco) and $10 \mathrm{~mL} / \mathrm{L}$ of a $2.5 \%(w / v)$ glucose solution (M1H ASW medium) or $20 \mathrm{~mL} / \mathrm{L}$ of a $5 \%(w / v)$ solution of $N$-acetyl-D-glucosamine (NAG ASW medium) as carbon and nitrogen sources. For the subsequent cultivation of novel strains, all media contained peptone, yeast extract and NAG as additional components (M1H NAG ASW) (Supplementary Table S1).

Algal attachment experiments were performed with media solely containing either $2 \mathrm{~g} / \mathrm{L}$ Ascophyllum nodosum (BioOrigins, Sandleheath, United Kingdom) or Fucus serratus 
(Mountain Fresh Health Foods, Twin Falls, ID, USA) powder. Biofilm suspensions and algal portions of Laminaria sp., Fucus sp., and Ulva sp. were prepared as described above and used to inoculate liquid and solid M1H ASW and NAG ASW medium (Supplementary Table S1). Solid media were inoculated either with $15 \mu \mathrm{L}$ biofilm suspension (spread out with glass beads) or one algal piece, which was swabbed over the plate and then placed in the middle. In addition, $100 \mathrm{~mL}$ liquid medium (M1H ASW medium and NAG ASW medium) were inoculated with either $100 \mu \mathrm{L}$ biofilm suspension or with one round algal piece. Addition of antibiotics served as selection pressure to enrich planctomycetes, which often turn out to be resistant to several antimicrobial agents, e.g., $\beta$-lactam antibiotics [43,44]. A floating filter cultivation technique was adapted from a previously published protocol [45]: 6-well inoculation plates (Corning Costar cell culture plates, Sigma-Aldrich) were filled with $5 \mathrm{~mL}$ of either M1H ASW or NAG ASW medium, supplemented with $100 \mathrm{mg} / \mathrm{L}$ cycloheximide and either $2000 \mathrm{mg} / \mathrm{L}$ carbenicillin or $1000 \mathrm{mg} / \mathrm{L}$ streptomycin. For inoculation, biofilm suspensions obtained from the three different algae were diluted 1:5, 1:10, and 1:50 in $5 \mathrm{~mL}$ sterile seawater and filtered through black polycarbonate filters $(0.1 \mu \mathrm{m}$ retention size, diameter $25 \mathrm{~mm}$, GE Osmonics, Minnetonka, MN, USA). The filters were then placed to float on the medium. All cultures were incubated in the dark at $20^{\circ} \mathrm{C}$ until colony growth or change in cell density (enrichment cultures) was observed. Cell densities were measured as optical density at $600 \mathrm{~nm}\left(\mathrm{OD}_{600}\right)$ using an Ultrospec II spectrophotometer (LKB Biochrom, Cambridge, United Kingdom). Colonies with certain phenotypes, e.g., a pink- or cream-colored pigmentation, smooth colony appearance and slow growth were replated. Enrichment cultures were checked for the enrichment of bacteria with characteristic traits of planctomycetes, such as polar budding or pear- to spherical cell shape [25], by wide-field microscopy and were subsequently plated on solid medium. Strains were identified by $16 \mathrm{~S}$ rRNA gene sequencing as previously described [46] and replated three times for purification after having confirmed that the strains are indeed members of the phylum Planctomycetes. Isolates with $16 \mathrm{~S}$ rRNA gene sequence identity values below $97 \%$ to any then-described isolate were considered as novel. Out of all strains isolated by the used methods, four strains $\left(\mathrm{K} 22.7^{\mathrm{T}}, \mathrm{FF} 11 \mathrm{~L}^{\mathrm{T}}, \mathrm{HG} 15 \mathrm{~A} 2^{\mathrm{T}}\right.$ and $\left.\mathrm{EC}{ }^{\mathrm{T}}\right)$ were subjected to a more detailed characterization.

\subsection{Determination of Temperature and $p H$ Optima for Growth}

Strains K22.7 ${ }^{\mathrm{T}}$, FF011L $\mathrm{L}^{\mathrm{T}}$, HG15A2 ${ }^{\mathrm{T}}$, and EC9 ${ }^{\mathrm{T}}$ were grown in M1H NAG ASW medium to the early stationary phase. This pre-culture was then used to inoculate medium (1:10 dilution) for determination of the temperature and $\mathrm{pH}$ optima for growth. For the determination of the optimal temperature for growth, temperatures of 10,12, 14, 16, 18, $20,22,24,26,28,32,34,36$, and $40^{\circ} \mathrm{C}$ were tested in duplicates. For the determination of the optimal pH, M1H NAG ASW medium buffered with MES, HEPES, HEPPS or CHES (10 mM final concentration) was used over a $\mathrm{pH}$ range from 5-10 in 0.5 steps. Cell densities were measured as optical density at $600 \mathrm{~nm}\left(\mathrm{OD}_{600}\right)$. Growth rates were obtained from the plot of $\ln \left(\mathrm{OD}_{600}\right)$ against the cultivation time.

\subsection{Catalase and Cytochrome Oxidase Activity}

Catalase activity was determined by reaction of cell material obtained from an exponentially growing culture with $3 \%(v / v) \mathrm{H}_{2} \mathrm{O}_{2}$ solution, resulting in the release of oxygen (catalase-positive). Cytochrome oxidase activity was determined using Bactident Oxidase test stripes (Merck Millipore, Darmstadt, Germany) following the manufacturer's instructions.

\subsection{Substrate Utilization}

Substrate utilization of strains K22.7 $7^{\mathrm{T}}$, FF011L $\mathrm{L}^{\mathrm{T}}, \mathrm{HG} 15 \mathrm{~A} 2^{\mathrm{T}}$, and EC9 ${ }^{\mathrm{T}}$ was determined using the Biolog GN2 MicroLog test panel for Gram-negative bacteria in duplicates. Sterile glass tubes were prepared in duplicates with a basic sterile medium mixture containing 14.2 mL IF-0a inoculation fluid (Biolog, Hayward, CA, USA), $1.6 \mathrm{~mL}$ of a $10 \times$ salt solution (containing per liter: $200 \mathrm{~g} \mathrm{NaCl}, 40 \mathrm{~g} \mathrm{Na}_{2} \mathrm{SO}_{4}, 30 \mathrm{~g} \mathrm{MgCl}_{2} \cdot 6 \mathrm{H}_{2} \mathrm{O}, 5 \mathrm{~g} \mathrm{KCl}, 2.5 \mathrm{~g} \mathrm{NH}{ }_{4} \mathrm{Cl}, 2 \mathrm{~g}$ 
$\mathrm{KH}_{2} \mathrm{PO}_{4}, 1.5 \mathrm{~g} \mathrm{CaCl}_{2} \cdot 2 \mathrm{H}_{2} \mathrm{O}$ ), $160 \mu \mathrm{L} 1 \mathrm{M} \mathrm{HEPES}$ buffer ( $\left.\mathrm{pH} 8.0\right), 80 \mu \mathrm{L}$ double concentrated vitamin solution, and $16 \mu \mathrm{L}$ trace element solution (for recipes, see [47]). Tubes were inoculated with bacterial colony material from exponentially growing cultures to a turbidity of 50-60\% transmittance using a turbidimeter (AES Chemunex BLG 3531). To enable the comparison of utilization values, the data of each single experiment were normalized to 100 . Only results $>0$ were taken into consideration. A heatmap of resulting values was computed using the R environment [48] with the heatmap.2() function of the gplots package, v. 3.1.0.

\subsection{Cellular Fatty Acid Analysis}

Biomass of the isolated strains was obtained from liquid cultures grown in M1H NAG ASW medium (Supplementary Table S1) at the respective optimal growth temperature until the stationary phase was reached. Cells of $50 \mathrm{~mL}$ culture were harvested by centrifugation at $10,000 \times g$ for 20 min (Avanti Centrifuge I-26 XPI, Beckman Coulter, Krefeld, Germany) and the supernatant was discarded. Then, $30 \mathrm{mg}$ of lyophilized biomass were analyzed by the Identification Service of the German Collection of Microorganisms and Cell Cultures (DSMZ) according to the standard protocols of the facility based on previously published methods $[49,50]$.

\subsection{Algal Attachment Assay}

To investigate the attachment and growth behavior of strain $\mathrm{K} 22.7^{\mathrm{T}}$, which was isolated from Fucus sp., an artificial marine snow (AMS) medium containing algal powder from the brown alga Fucus serratus as sole carbon and nitrogen source was prepared. Since the AMS medium was very dark in color and contained a lot of algal particles, $\mathrm{OD}_{600}$ determination for assessing the growth of the planctomycete was not possible.

\subsection{DNA Isolation and Amplification for Sequence-Based Community Analysis}

DNA of algal biofilms and water filters was extracted using the PowerBiofilm DNA Isolation Kit (MoBio Laboratories, Carlsbad, CA, USA) following the manufacturer's protocol with a few exceptions: incubation at $37^{\circ} \mathrm{C}$ in buffer B1 was increased to an overnight step; incubation at $55{ }^{\circ} \mathrm{C}$ was increased to $60 \mathrm{~min}$; incubation at $4{ }^{\circ} \mathrm{C}$ was increased to $20 \mathrm{~min}$. Bead-beating was performed in a FastPrep-24 instrument (MP Biomedicals, Eschwege, Germany) at $5.5 \mathrm{~m} / \mathrm{s}$ for $30 \mathrm{~s}$. DNA was eluted in $100 \mu \mathrm{L} \mathrm{BF7} \mathrm{buffer} \mathrm{and} \mathrm{stored} \mathrm{at}-20{ }^{\circ} \mathrm{C}$ until further processing. The DNA was quantified using the Qubit dsDNA HS or BR Assay Kits (Thermo Fisher Scientific, Dreieich, Germany). Genomic DNA was amplified by multiple displacement amplification (MDA) based on phage $\Phi 29$ (phi29) DNA polymerase [51]. For this purpose, the Illustra GenomiPhi V3 DNA Amplification Kit (GE Healthcare, Solingen, Germany) [52] was used following the general recommendations of the manufacturer. For one single amplification reaction ( $20 \mu \mathrm{L}$ total volume), $1 \mathrm{ng}$ of genomic DNA was used. To reduce remaining stochastic amplification bias, three independent reactions per sample were pooled. To reduce contamination with external DNA, preparation steps not involving a DNA template were performed in a PCR cabinet (AirCleanSystems, StarLab, Hamburg, Germany) previously decontaminated using DNA-away (Molecular BioProducts, Thermo Fisher Scientific, Dreieich, Germany) and UV light for $1 \mathrm{~h}$ in a no-template room. DNA was added in another low-template room in a second PCR cabinet and amplification reactions were performed in a thermal cycler (Veriti 96-Well, Applied Biosystems, Waltham, MA, USA). MDA-amplified DNA was stored at $-20^{\circ} \mathrm{C}$ until further processing.

Amplification of the variable region 3 (V3) of 16S rRNA genes was performed using two subsequent PCR amplifications. The first protocol was used to enrich the V3 region of MDA-obtained DNA. In this protocol, the universal forward primer 341f (5'-CCT ACG GGW GGC WGC AG-3') and the reverse primer uni515r (5'-CCG CGG CTG CTG GCA C-3') (modified from 518r) [53] were used. The second PCR protocol was then performed with extended V3 region primers V3F (5'-AAT GAT ACG GCG ACC ACC GAG ATC TAC ACT CTT TCC CTA CAC GCT CTT CCG ATC TCC TAC GGG WGG CWG CAG- 
$3^{\prime}$ ) and indexed V3R primers (5'-CAA GCA GAA GAC GGC ATA CGA GAT XXX XXX GTG ACT GGA GTT CAG ACG TGT GCT CTT CCG ATC TCC GCG GCT GCT GGC AC- $3^{\prime}$ ) (modified from [54]). Sample/index combinations are listed in Supplementary Table S2. PCR reactions for the first protocol of $50 \mu \mathrm{L}$ contained 25-29 $\mu \mathrm{L}$ microbial DNA-free water (Qiagen, Hilden, Germany), $10 \mu \mathrm{L} 5 \times$ Q5 Reaction Buffer (New England Biolabs, Frankfurt am Main, Germany), $10 \mu \mathrm{L} 5 \times$ Q5 High GC Enhancer (New England Biolabs), $1 \mu \mathrm{L}$ dNTP Mix (final concentration $200 \mu \mathrm{M}$, New England Biolabs), $0.5 \mu \mathrm{L}$ of each primer (341f and uni515r, final concentration $0.1 \mu \mathrm{M}$ ), $0.5 \mu \mathrm{L}$ Q5 High fidelity DNA Polymerase (final concentration $0.02 \mathrm{U} / \mu \mathrm{L}$, New England Biolabs) and 1-5 $\mu \mathrm{L}$ MDA-amplified gDNA ( $500 \mathrm{ng})$. The cycling program consisted of an initial denaturation step at $94{ }^{\circ} \mathrm{C}, 5 \mathrm{~min}$, followed by 10 cycles of denaturation at $94{ }^{\circ} \mathrm{C}, 1 \mathrm{~min}$, annealing at $63{ }^{\circ} \mathrm{C}, 1 \mathrm{~min}$, elongation at $72{ }^{\circ} \mathrm{C}, 1 \mathrm{~min}$, and a final elongation step at $72{ }^{\circ} \mathrm{C}, 10 \mathrm{~min}$. Three independent preamplification reactions were pooled and stored at $4{ }^{\circ} \mathrm{C}$ until further processing. The next PCR amplification was performed to add sequence indices and adapter sequences for subsequent Illumina sequencing. PCR reactions of $50 \mu \mathrm{L}$ contained $13.1 \mu \mathrm{L}$ PCR-grade $\mathrm{H}_{2} \mathrm{O}$ (Qiagen, Hilden, Germany), $10 \mu \mathrm{L} 5 \times$ Q5 Reaction Buffer (New England Biolabs), $10 \mu \mathrm{L}$ $5 \times$ Q5 High GC Enhancer (New England Biolabs), $1 \mu \mathrm{L}$ dNTP Mix (final concentration $200 \mu \mathrm{M}$, New England Biolabs), $0.2 \mu \mathrm{L}$ of each primer (V3F and V3R, final concentration $0.2 \mu \mathrm{M}$ ), $0.5 \mu \mathrm{L}$ Q5 High fidelity DNA Polymerase (final concentration $0.02 \mathrm{U} / \mu \mathrm{L}$, New England Biolabs) and $10 \mu \mathrm{L}$ PCR product of the first PCR as DNA template. Amplification was performed with a cycling program including an initial denaturation step at $98^{\circ} \mathrm{C}$, $5 \mathrm{~min}$, followed by 10 cycles of denaturation at $98^{\circ} \mathrm{C}, 1 \mathrm{~min}$, annealing at $65^{\circ} \mathrm{C}, 1 \mathrm{~min}$, elongation at $72{ }^{\circ} \mathrm{C}, 1 \mathrm{~min}$ and a final elongation step at $72{ }^{\circ} \mathrm{C}, 5 \mathrm{~min}$. To reduce stochastic amplification bias, three independent amplifications were performed. Amplicon PCR products were separated by agarose gel electrophoresis $(2 \%(w / v)$ agarose, Serva) in $1 \times$ TRIS-acetate-EDTA buffer (Applichem, Darmstadt, Germany) at $130 \mathrm{~V}$ for $90 \mathrm{~min}$. The gel was stained with SYBR gold nucleic acid gel stain (Thermo Fisher Scientific) for $60 \mathrm{~min}$ and DNA was visualized by UV light. Amplicon bands (fragment size of $\sim 300 \mathrm{bp}$ ) were cut out and extracted using the NucleoSpin Gel and PCR Clean-up kit (Macherey-Nagel, Dueren, Germany). All three replicates of each sample were purified over the same column.

\subsection{Amplicon Sequencing and Sequence Processing}

Reads of V3 amplicons obtained from Illumina multiplex sequencing (MiSeq) were quality trimmed using the tool Trimmomatic v. 0.36 [55] with the following arguments: "LEADING:3 TRAILING:3 SLIDINGWINDOW:4:15 MINLEN:105". The trimmed sequences were then filtered for those starting with the forward and ending with the reverse primer. The remaining sequences were subsequently checked for chimera using UCHIME [56]. Non-chimeric sequences were further processed by clipping the forward and the reverse primer sequences and applying a length filter for sequences between 120 and $167 \mathrm{bp}$. Sequences below or above this cut-off were found to be chimeric sequences that were not detected by the UCHIME algorithm. The processed sequences were submitted to SILVAngs for taxonomic classification [57]. Files were uploaded as suggested in the SILVAngs user-guide and data were processed by the SILVAngs software according to the protocol, including alignment with the SINA aligner [58]. During the process, a de-replication step, eliminating $100 \%$ identical reads by only processing the longest read, as well as operational taxonomic unit (OTU) definition and clustering [59] were performed. OTUs were classified by a local BLAST search using blastn with default parameters in accordance with the non-redundant version of the SILVA SSU Ref database [57].

\subsection{Wide Field Microscopy}

Cells of the four isolated strains were immobilized on a 1\% $(w / v)$ agarose-pad in MatTek $35 \mathrm{~mm}$ glass-bottom dishes and imaged under phase-contrast illumination using a Nikon Eclipse Ti inverse microscope at 100-fold magnification and employing a Nikon DS-Ri2 camera. To determine the cell size of the novel strains, 100 individual cells of 
each strain were measured using the NIS-Elements software V4.3 (Nikon Instruments, Amsterdam, The Netherlands). Z-stacks were imaged to visualize algal attachment. To increase overall sharpness of phase contrast images, $z$-stacks were processed with the software PICOLAY (www.picolay.de, accessed on 15 June 2015) using the focus stacking option. By using this option, the program takes the sharp areas of each stack, generating a single overall sharp picture.

\subsection{Field Emission Scanning Electron Microscopy (SEM) of Bacteria, Biofilms on Algal Pieces and Algae Granules}

After cultivation of the isolated strain $\mathrm{K} 22.7^{\mathrm{T}}$ with Fucus serratus powder (Mountain Fresh, Health Foods, Twin Falls, ID, USA), algal particles and attached bacteria were fixed in modified HEPES buffer ( $3 \mathrm{mM}$ HEPES, $0.3 \mathrm{mM} \mathrm{CaCl}, 0.3 \mathrm{mM} \mathrm{MgCl} 2,2.7 \mathrm{mM}$ sucrose, $\mathrm{pH}$ 6.9) containing $1 \%(v / v)$ formaldehyde for $1 \mathrm{~h}$ on ice and were washed once with the same buffer. The same protocol was used for the fixation of axenic cultures of the isolated planctomycetal strains. Cover slips with a diameter of $12 \mathrm{~mm}$ were coated with $50 \mu \mathrm{L}$ of a $0.1 \%(w / v)$ poly-L-lysine solution (Sigma-Aldrich) for $10 \mathrm{~min}$, washed with distilled water and air-dried. Algal pieces or $50 \mu \mathrm{L}$ of the fixed bacteria solution were placed on a cover slip and allowed to settle for $10 \mathrm{~min}$. Cover slips were then fixed in $1 \%(v / v)$ glutaraldehyde in TE buffer (20 mM TRIS, $1 \mathrm{mM}$ EDTA, pH 6.9) for 5 min at room temperature and subsequently washed twice with TE buffer before dehydrating in a graded series of acetone $(1.5 \mathrm{~mL}$ each of $10 \%, 30 \%, 50 \%, 70 \%, 90 \%, 100 \%(v / v))$ on ice for $10 \mathrm{~min}$ at each concentration. Samples from the $100 \%$ acetone step were brought to room temperature before placing them in $20 \mathrm{~mL}$ fresh $100 \%$ acetone. Samples were then subjected to critical point drying with liquid $\mathrm{CO}_{2}$ (CPD 300, Leica). Dried samples were covered with a gold/palladium (80/20) film by sputter coating (SCD 500, Bal-Tec, Leica Biosystems, Wetzlar, Germany) before examination in a field emission scanning electron microscope (Zeiss Merlin, Jena, Germany) using the Everhart Thornley HESE2-detector and the inlens SE-detector in a 25:75 ratio at an acceleration voltage of $5 \mathrm{kV}$.

\subsection{Transmission Electron Microscopy (TEM)}

Thin sections of strains $\mathrm{K} 22.7^{\mathrm{T}}$, FF011L $\mathrm{L}^{\mathrm{T}}$, HG15A2 ${ }^{\mathrm{T}}$, and $\mathrm{EC} 9^{\mathrm{T}}$ were prepared by high pressure freezing and freeze substitution as previously described [60]. Sections were subsequently analyzed employing a JEOL 1200EX $80 \mathrm{kV}$ TEM microscope.

\subsection{Genome Information of the Isolated Strains}

The genomes of all strains were published previously [39] and are available from RefSeq under accession numbers CP036261 (EC9 $\left.{ }^{\mathrm{T}}\right), \mathrm{CP} 036262\left(\mathrm{FF}^{2} 11 \mathrm{~L}^{\mathrm{T}}\right), \mathrm{CP} 036263\left(\mathrm{HG}_{15 A 2}{ }^{\mathrm{T}}\right)$ and $\mathrm{CP} 036525\left(\mathrm{~K} 22.7^{\mathrm{T}}\right)$. The GenBank accession numbers of the respective $16 \mathrm{~S}$ rRNA genes are MK554523, MK559974, MK559975, and MK559976.

\subsection{Construction of Phylogenetic Trees}

Maximum likelihood 16S rRNA gene sequence-based phylogeny was computed for the novel strains, all described planctomycetal species of the order Pirellulales [28-31,40,42,61-73] and an outgroup of three strains from the order Planctomycetales (acc. no. MK554524, MK554557, and X62911). The 16S rRNA gene sequences were aligned with SINA [58]. The phylogenetic analysis was then done by employing a maximum likelihood approach with 1000 bootstraps, the nucleotide substitution model GTR, gamma distribution and estimation of proportion of invariable sites (GTRGAMMAI option) [74].

For the multilocus sequence analysis (MLSA), the unique single-copy core genome of all analyzed genomes was determined with proteinortho5 [75] with the 'selfblast' option enabled, a coverage of $50 \%$, and an e-value of $1 \mathrm{e}-05$. The protein sequences of the resulting orthologous groups were aligned using MUSCLE v.3.8.31 [76]. After clipping, partially aligned $C$ - and $N$-terminal regions and poorly aligned internal regions were filtered using Gblocks [77]. The final alignment of 570 ubiquitous genes with a combined length of 292,572 conserved amino acid residues was concatenated and clustered using FastTree [78]. 
The outgroup consisted of three genomes from strains of the order Planctomycetales (acc. no. CP036342, CP036347, and CP001744). Visualizations were performed with iToL v.4 [79].

Members of the novel genus Roseiconus [73] clustered within the earlier described genus Stieleria [40,62]. The results for both genera are therefore summarized under the latter term for all analyses.

\subsection{Analysis of Phylogenetic Markers}

The $r p o B$ nucleotide sequences encoding the RNA polymerase $\beta$-subunit were taken from the respective, previously published genomes and the sequence identities were determined as described before [80] using Clustal Omega [81]. Alignment and matrix calculation were performed only using those parts of the sequence that would have been sequenced with the described primer set. The average nucleotide identity (ANI) was calculated using OrthoANI [82]. The average amino acid identity (AAI) was obtained with the aai.rb script of the enveomics collection [83] and the percentage of conserved proteins (POCP) was calculated as described before [84].

\subsection{Analysis of Genome-Encoded Features}

A genome-based analysis of encoded enzymes participating in central carbon metabolism was conducted by examining locally computed InterProScan [85] results crossreferenced with information from the UniProt [86] database and BLASTp results of typical protein sequences. The prediction of biosynthetic gene clusters for the analysis of secondary metabolites and small molecules was performed with antiSMASH 5 locally (enabled parameters: cb-general, cb-knownclusters, cb-subclusters, asf, pfam2go, smcog-trees, genefinding-tool prodigal) [87]. The analysis of the pan and core genomes was undertaken with anvi'o [88], following the pangenomics workflow [89].

\section{Results}

To explore the epiphytic bacterial communities of macroalgae found at the shore of Helgoland Island, the only German high seas island, we sampled organisms of three different genera, namely the brown algae Laminaria sp., Fucus sp., as well as the green alga Ulva sp. All specimens were conserved appropriately and subjected to cultivationindependent analyses and used for the cultivation of novel bacterial taxa.

\subsection{Bacterial Communities of North Sea Algae Surfaces}

In a first step, the bacterial communities associated with the macroalgae were investigated by amplification and sequencing of the $16 \mathrm{~S}$ rRNA gene V3 region. Both, algal biofilms and surrounding waters were included in the analysis after the water samples were split into two fractions by filtration $(2.7 \mu \mathrm{m}$ filter retention size) to be able to target the planktonic bacteria and the surrounding aggregates and particles individually. For each of the nine samples (Figure 1), between 32,381 and 133,343 reads resulting in 546-1252 OTUs were obtained (Supplementary Table S3).

At the phylum level (Figure 1A), Laminaria sp. and Ulva sp. communities were rather similar despite the distant relation of the two host organisms. Both were dominated by Proteobacteria (63.2\% and 49.7\%, respectively). Two other major taxa were the Bacteroidetes (6.5\% and 26.3\%) and Epsilonbacteraeota (24.2\% and 20.5\%). Other lineages, including Verrucomicrobia, Planctomycetes, Patescibacteria (Candidate Phyla Radiation), Fusobacteria, Kiritimatiellaeota, and Firmicutes, were present, but each constituted $<1.8 \%$ of the biofilms. In comparison with the Laminaria sp. and Ulva sp.-associated communities, the general composition of the surrounding particles and planktonic bacteria only changed slightly (Figure 1A): while the Bacteroidetes gained dominance over the Proteobacteria, Verrucomicrobia and Planctomycetes also became more prominent. In recent years, Ulva sp. biofilms have been analyzed in particular and were often shown to be primarily composed of Alphaproteobacteria and Bacteroidetes, often followed by Gammaproteobacteria, Actinobacteria, Firmicutes, Cyanobacteria, Verrucomicrobia, and Planctomycetes [8,10,12,14-16]. Our results 
are mostly consistent with these results, with exception to the high abundance of Epsilonbacteraeota and the absence of considerable amounts of Actinobacteria and Cyanobacteria. The identification of taxa such as Patescibacteria and Kiritimatiellaeota might be explained by the only recent work that was dedicated towards these clades and now enables their detection [90-92]. In contrast to other studies [10,16], the dominant Proteobacteria were not Alphaproteobacteria, but Gammaproteobacteria, which constituted between $78.7 \%$ and $90.3 \%$ of the total Proteobacteria and primarily included Alteromonadales (81.3\% of Gammaproteobacteria on Laminaria sp.) or Thiotrichales (42.6\% of Gammaproteobacteria on Ulva sp.), followed by Oceanospirillales and Vibrionales. Interestingly, Gammaproteobacteria, in particular taxa of the orders Alteromonadales and Oceanospirillales, were found to be highly abundant in young marine biofilms [93] and might be used as an indicator for the age of the examined biofilms.
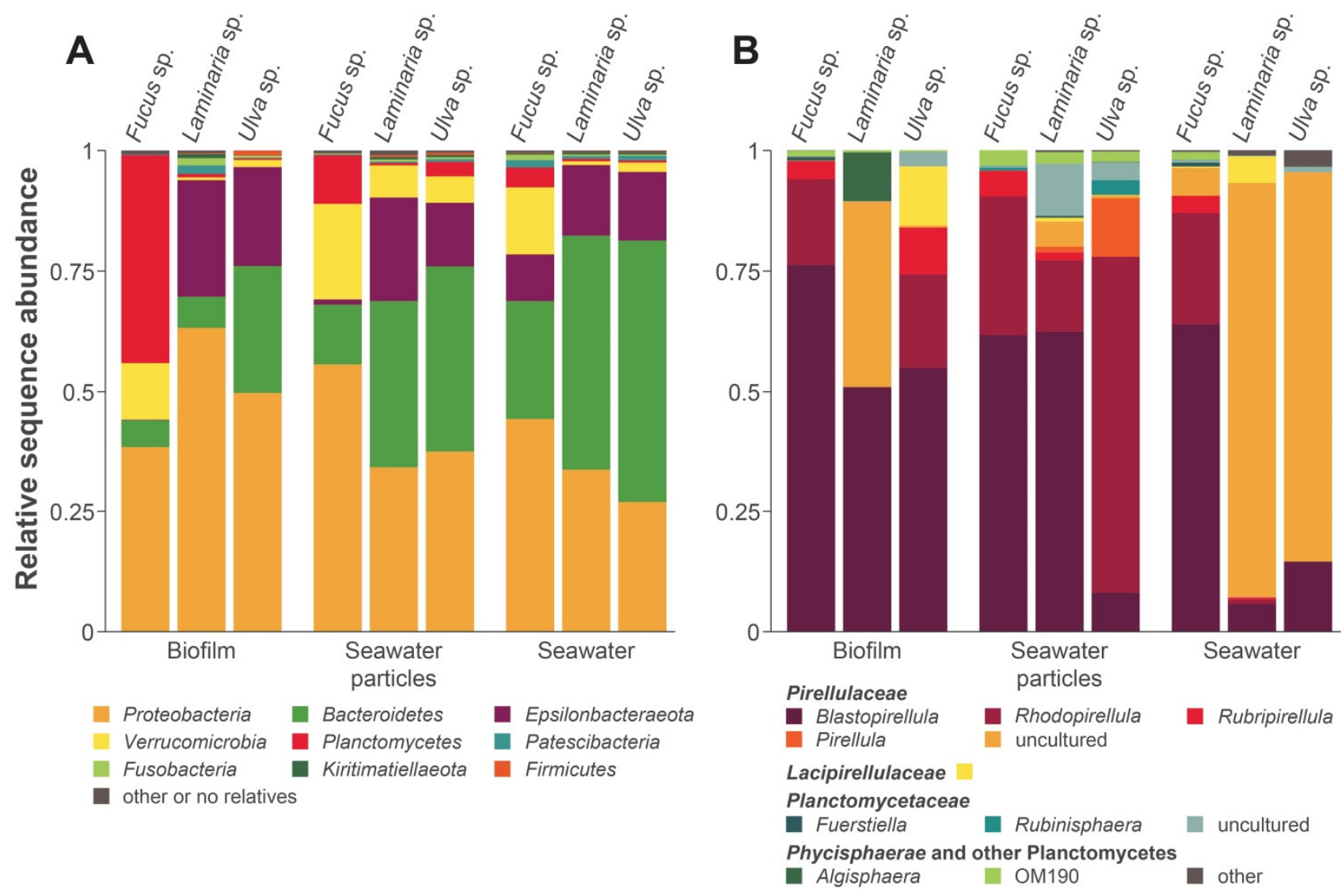

Figure 1. Bacterial epiphytic community on different macroalgae. The composition of the biofilms was analyzed based on 16S rRNA gene sequence-determined taxonomic classification on phylum level (A) and, for Planctomycetes, on genus level (B). The examined samples were taken from the algal biofilms and the surrounding waters which were subdivided in particles and aggregates (seawater particles) and planktonic bacteria (seawater). Taxa with an abundance $<1 \%$ are summarized as "other (or no relative)". The numbers of sequences, average length and numbers of operational taxonomic units are provided in Table S3.

The epiphytic bacterial community of Fucus sp. was significantly different to the other two macroalgae. The phylum Planctomycetes represents the dominant fraction of the bacterial community in the biofilm (43.1\%), followed by Proteobacteria (38.5\%), Verrucomicrobia (11.7\%), and Bacteroidetes (5.6\%). In the samples of the surrounding waters, Planctomycetes lost their high prevalence, while Bacteroidetes, Verrucomicrobia and Proteobacteria became more abundant. High abundances of Planctomycetes on Fucus sp. biofilms have been described previously in co-occurrence with Rhodobacterales, Gammaproteobacteria, Bacteroidetes and Verrucomicrobia [16]. However, these results were not a consistent finding for all examined Fucus sp. [16,94]. 
Macroalgae as well as other photosynthetic surface biofilms have been described as communities with at times very high abundances of members of the phylum Planctomycetes [10,12,14-16,22,25]. Encouraged by these findings and the high abundance of Planctomycetes, especially on Fucus sp., we examined this phylum on a more resolved level (Figure 1B). It turned out that Blastopirellula sp. were dominant in all planctomycetal fractions of the Laminaria sp., Ulva sp., and Fucus sp. biofilms (50.9\%, 54.9\%, and $76.2 \%$, respectively). Furthermore, the Ulva sp. and Fucus sp. biofilms were occupied by Rhodopirellula sp. (19.4\% and 17.8\%), Rubripirellula sp. (9.7\% and 3.8\%), and members of the family Lacipirellulaceae (12.3\% and $0.1 \%$ ). Instead, the Laminaria sp. epiphytic community was not formed by these latter taxa, but comprised yet uncultured members of the family Pirellulaceae (38.5\%). Other noteworthy taxa of the Planctomycetes found in the macroalgae surface microbiome were classified as constituents of the family Planctomycetaceae, Algisphaera sp. (class Phycisphaerae) and the OM190 lineage. The diversity of the particleassociated water fractions of Fucus sp. and Laminaria sp. was similar to their biofilm composition, whereas Ulva sp. adjacent particles contained high amounts of Rhodopirellula sp. (69.8\%) and Pirellula sp. (12.1\%), a genus which was only found as a minority in all other samples. A similarity of the planktonic fraction to the biofilm was still found for Fucus sp., but the other seawater fractions mainly comprised uncultured Pirellulaceae. Several earlier studies focused specifically on planctomycetes found on macroalgae. In accordance with our results, all of the identified taxa could be allocated to the families Pirellulaceae, Lacipirellulaceae, Planctomycetaceae and OM190 lineage [20,21,23]. Blastopirellula was found as the dominant genus on Fucus sp. as well as Ulva sp. sampled at the Portuguese coast, followed by Rhodopirellula sp. and other Pirellulaceae [19]. These results were validated by our samples from Helgoland Island, emphasizing that epiphytic macroalgal communities seem to be rather independent of their geographic location $[9,19,20]$.

In a second step, the algae samples were analyzed by field emission scanning electron microscopy (FESEM) to determine the different morphologies of the algae-associated surface biofilms. Figure 2 shows the biofilm composition of the sampled Fucus sp., Laminaria sp., and Ulva sp. specimens. Fucus biofilms were by far the densest, with less than $5 \%$ algal surface visible in all FESEM images ( $n=16$; visual inspection and estimation). While most bacteria appear spherical or rod-shaped with one pole thicker than the other, chains of coccoid cells and tubular-like microorganisms were also visible. In comparison, biofilms of Laminaria sp. and Ulva sp. were less dense and more non-colonized areas were visible. Laminaria sp. biofilms were dominated by rod-shaped bacteria, with about $25-50 \%$ of the algal surface lacking microbial epibionts $(n=16)$. Biofilms of the Ulva sp. surface showed a very similar degree of colonization as the Laminaria sp. samples, while more chain-forming microorganisms were present, and the diversity of bacterial morphologies seemed less broad. A lot of spherical cells with evenly distributed fibers around the whole cell body were visible. While the majority of the microorganisms found on all macroalgae seemed to be dividing by binary fission, budding bacteria could also be spotted on all algal samples (Figure 2, orange arrowheads). However, it is uncertain if these cells belong to members of the class Planctomycetia found in all epiphytic communities or if they are members of other budding species. The latter might also be the case since between $1.3 \%$ and $1.7 \%$ of the found OTUs are derived from non-planctomycetal, but budding bacteria, such as members of the Hyphomonadaceae, Rhodobacteraceae, or Alteromonadaceae. Nevertheless, the abundance of Planctomycetes was 0.5-14-fold higher than those of the other budding bacteria, making them an excellent target for further investigation. 

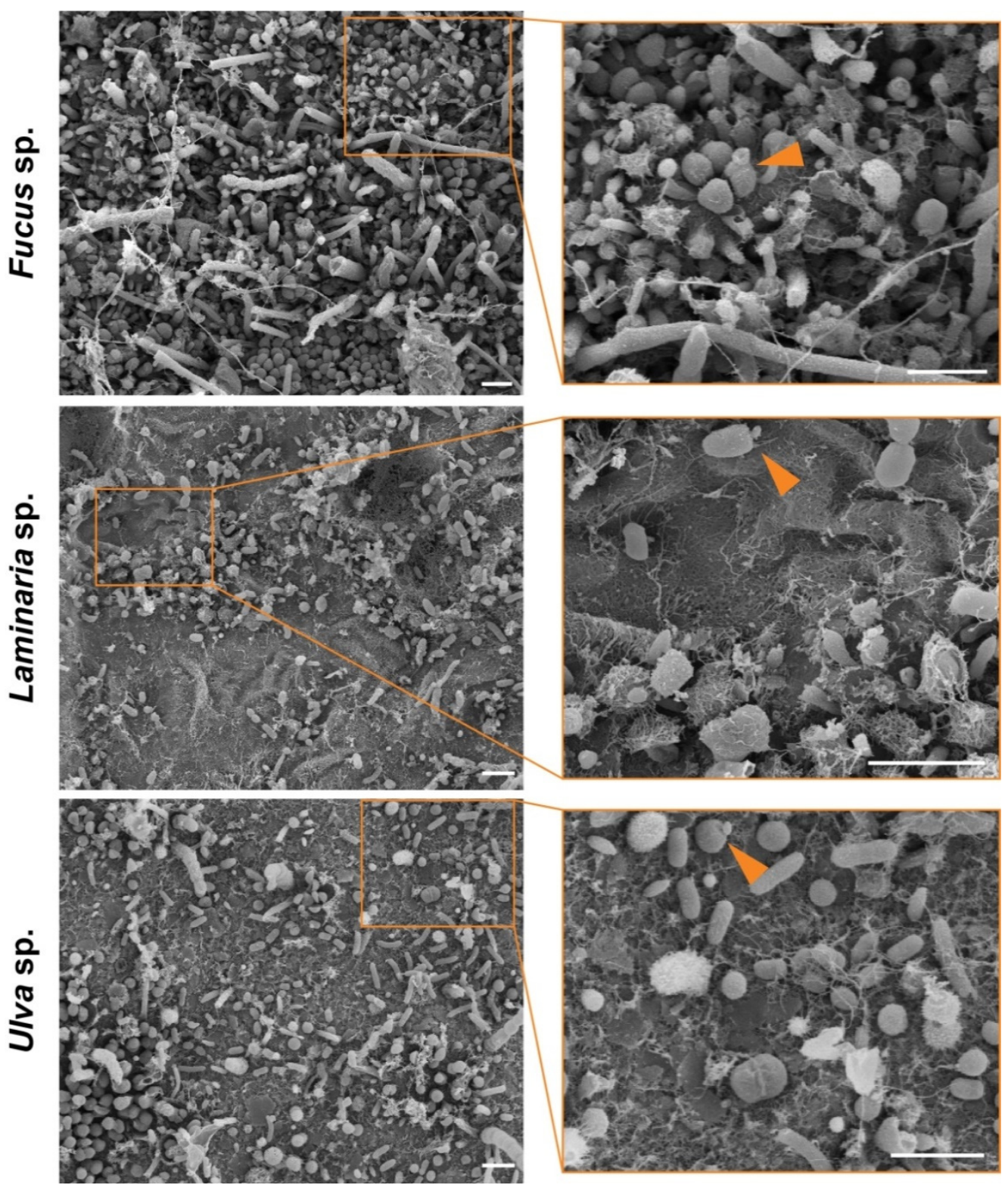

Figure 2. Morphological characteristics of Fucus sp., Laminaria sp. and Ulva sp. biofilms. Overview images (left) representatively show the morphological differences between the epiphytic biofilm communities on the surfaces of the different algae. Close-ups (right) indicate bacteria which showed budding reproduction by arrowheads, possibly being members of the phylum Planctomycetes. Scale bar: $2 \mu \mathrm{m}$.

\subsection{Cultivation-Dependent Targeted Isolation of Novel Planctomycetal Strains}

The $16 \mathrm{~S}$ rRNA gene sequence-based analyses and the observation of budding bacteria in the epiphytic communities colonizing the different types of sampled macroalgae both pointed towards the considerable abundance of members of the phylum Planctomycetes within the algae-associated biofilms and the surrounding waters. Therefore, we pursued the targeted cultivation of novel planctomycetal strains to obtain axenic cultures of yet uncharacterized taxa.

In initial attempts inoculating media with algae pieces or filters, we mainly obtained fungi, which overgrew the plates within $2-5$ days. This observation was made for solid media, liquid enrichment cultures, as well as floating filter assays. To overcome this predicament, we optimized the cultivation conditions by carefully titrating antimicrobial 
agents, including anti-fungal agents. Together with a pre-treatment of the sample material, fungal growth was eliminated during the initial and subsequent cultivations.

We also used antibiotics, either carbenicillin or a combination of ampicillin and streptomycin (Supplementary Table S1), against which many known planctomycetes were found to be resistant [44], to inhibit the growth of sensitive bacteria from other bacterial phyla, especially those proliferating considerably faster than planctomycetes. In general, the total number of colonies obtained was higher on peptone/yeast extract-based M1H ASW medium ( 80-100 colonies per plate; growth in enrichment cultures after 4-20 days) than on NAG ASW medium ( 5-20 colonies per plate; growth in enrichment cultures after 25-90 days), which only contains $\mathrm{N}$-acetyl-D-glucosamine as sole carbon and nitrogen source and lacks any complex ingredients. Microscopic analyses showed that M1H ASW medium enriched a broad spectrum of bacteria, even in the presence of carbenicillin (C) or a combination of ampicillin and streptomycin (A/S). Colonies obtained from NAG ASW cultures, however, showed planctomycetal morphology more often and especially cultures containing antibiotic agents were highly enriched in bacteria with planctomycetal morphotypes.

Especially A/S media were more effective in promoting planctomycetal growth, while carbenicillin tended to reduce the overall colony count. Growth on A/S media was delayed by an average time of $\sim 30$ days until first colonies or change of optical density was noted. From the cultivation methods used, biofilm plating, swabbing of algal pieces on solid media, and plating of enrichment cultures from highly selective medium (NAG ASW $+\mathrm{A} / \mathrm{S}$ ) on the corresponding solid medium proved to be the most effective method for selective cultivation of many planctomycetes. Using the floating-filter approach or less selective media, however, fell shorter with respect to the achievement of this goal.

Colonies of strains with 'planctomycetal phenotypes' (pink/red/cream pigmentation and/or budding as cell division mode) were subjected to $16 \mathrm{~S}$ rRNA gene sequencing. When applying a threshold of $<97 \% 16 \mathrm{~S}$ rRNA gene sequence identity, four strains unique by the time of the wet-lab work were identified: K22.7 (isolated from Fucus sp. biofilm plating), $\mathrm{FF} 011 \mathrm{~L}^{\mathrm{T}}$ (isolated from Laminaria sp. floating filter assay), $\mathrm{HG} 15 \mathrm{~A} 2^{\mathrm{T}}$ (isolated from Laminaria sp. biofilm plating) and $\mathrm{EC} 9^{\mathrm{T}}$ (isolated from an Ulva sp. enrichment culture), all of them being members of the recently described order Pirellulales [63].

\subsection{Physiological and Chemotaxonomic Characteristics of the Isolates}

Starting from the axenic cultures obtained for strains K22.7 ${ }^{\mathrm{T}}, \mathrm{FF} 011 \mathrm{~L}^{\mathrm{T}}, \mathrm{HG} 15 \mathrm{~A} 2^{\mathrm{T}}$, and $\mathrm{EC} 9^{\mathrm{T}}$, we conducted additional experiments in order to characterize important physiological and chemotaxonomic characteristics. During cultivation of the strains, all four turned out to be chemoorganoheterotrophs capable of using $N$-acetyl-D-glucosamine as sole carbon and nitrogen source, but with a preference for a more complex medium also containing peptone, yeast extract, and glucose. The strains displayed a mesophilic growth profile (Figure 3, Table 1), with a tolerated temperature range starting at $10^{\circ} \mathrm{C}$ and rising to temperatures from $26^{\circ} \mathrm{C}$ (strain HG15A2 $2^{\mathrm{T}}$ ) to $37^{\circ} \mathrm{C}$ (strain $\mathrm{K} 22.7^{\mathrm{T}}$ ). The optimal growth temperatures $\left(\mathrm{T}_{\text {opt }}\right)$ fall between $22{ }^{\circ} \mathrm{C}$ (strain HG15A2 ${ }^{\mathrm{T}}$ ) and $30^{\circ} \mathrm{C}\left(\right.$ strain $\left.\mathrm{EC} 9^{\mathrm{T}}\right)$. The maximal growth rates at $\mathrm{T}_{\text {opt }}$ (Table 1) in M1H NAG ASW medium were calculated to be between 0.018 and $0.062 \mathrm{~h}^{-1}$ which corresponds to doubling times between approximately $11 \mathrm{~h}\left(\right.$ strain EC9 ${ }^{\mathrm{T}}$ ) and $39 \mathrm{~h}\left(\right.$ strain HG15A2 ${ }^{\mathrm{T}}$ ). We observed a clear correlation of higher $\mathrm{T}_{\text {opt }}$ and higher growth rates between the analyzed strains. 

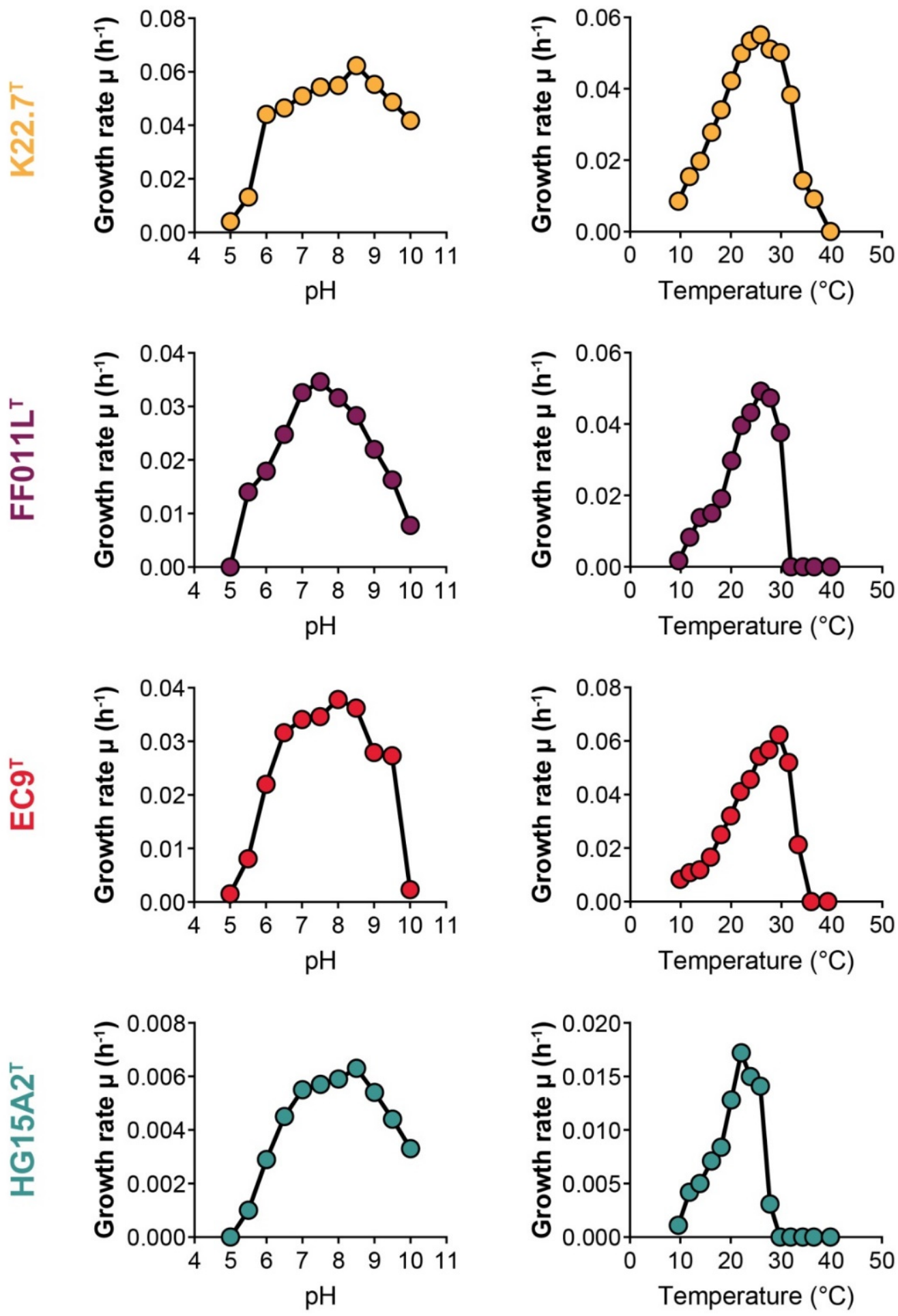

Figure 3. Temperature and pH optima of strains $\mathrm{K} 22.7^{\mathrm{T}}, \mathrm{FF} 011 \mathrm{~L}^{\mathrm{T}}, \mathrm{EC} 9^{\mathrm{T}}$ and $\mathrm{HG} 15 \mathrm{~A} 2^{\mathrm{T}}$. Growth was determined by optical density measurements at $600 \mathrm{~nm}$ and growth rates were calculated for cultures during the exponential phase. Each dot represents the mean of duplicate measurements. 
Table 1. Morphological, physiological and chemotaxonomic characteristics of the novel strains.

\begin{tabular}{|c|c|c|c|c|}
\hline Feature & $\mathrm{K} 22.7^{\mathrm{T}}$ & FF011L $L^{T}$ & $\mathrm{EC}^{\mathrm{T}}$ & $\mathrm{HG}_{15 \mathrm{~A} 2^{\mathrm{T}}}$ \\
\hline Arrangement of cells & $\begin{array}{c}\text { Rosettes and } \\
\text { aggregates }\end{array}$ & $\begin{array}{c}\text { Rosettes and } \\
\text { aggregates }\end{array}$ & $\begin{array}{c}\text { Rosettes and } \\
\text { aggregates }\end{array}$ & $\begin{array}{c}\text { Rosettes and } \\
\text { aggregates }\end{array}$ \\
\hline $\begin{array}{l}\text { Cell size }(\mu \mathrm{m}) \\
\text { Cell shape }\end{array}$ & $\begin{array}{c}2.5 \pm 0.4 \times 1.4 \pm 0.3 \\
\text { pear }\end{array}$ & $\begin{array}{c}2.0 \pm 0.3 \times 1.0 \pm 0.2 \\
\text { pear }\end{array}$ & $\begin{array}{c}2.4 \pm 0.3 \times 1.2 \pm 0.2 \\
\text { elongated pear }\end{array}$ & $\begin{array}{c}1.8 \pm 0.2 \times 1.3 \pm 0.2 \\
\text { egg }\end{array}$ \\
\hline Isolation source & Fucus sp. biofilm & Laminaria sp. biofilm & Ulva sp. biofilm & Laminaria sp. biofilm \\
\hline Isolation method & Biofilm plating & Floating filter assay & Enrichment cultivation & Biofilm plating \\
\hline Colony color & pink & pink to red & red & cream \\
\hline Respiration & aerobic & aerobic & aerobic & aerobic \\
\hline Oxidase activity & + & + & + & + \\
\hline Catalase activity & + & + & + & + \\
\hline Temperature range $\left({ }^{\circ} \mathrm{C}\right)$ & $10-37$ & $12-30$ & $10-33$ & $12-28$ \\
\hline $\mathrm{T}_{\text {opt }}\left({ }^{\circ} \mathrm{C}\right)$ & 26 & 26 & 30 & 22 \\
\hline $\mathrm{pH}$ range & $5.5-10.0$ & $5.5-10.0$ & $5.5-9.5$ & $5.5-10.0$ \\
\hline $\mathrm{pH}_{\mathrm{opt}}$ & 8.5 & 7.5 & 8.0 & 8.5 \\
\hline Growth rate at $T_{o p t}$ & 0.053 & 0.049 & 0.062 & 0.018 \\
\hline Generation time $(\mathrm{h})$ at $\mathrm{T}_{\mathrm{opt}}$ & 13.0 & 14.1 & 11.1 & 38.7 \\
\hline Major fatty acid component (\%) & $\mathrm{C}_{18: 1} \omega 9 \mathrm{c}(42.5)$ & $\mathrm{C}_{18: 1} \omega 9 \mathrm{c}(55.1)$ & $\mathrm{C}_{16: 0}(37.3)$ & $\mathrm{C}_{18: 1} \omega 9 \mathrm{c}(34.8)$ \\
\hline
\end{tabular}

The $\mathrm{pH}$ tolerance was broad for all strains, spanning a range from $\mathrm{pH} 5.0$ or 5.5 to pH 10.0 (Figure 3, Table 1). The optima for growth were $\mathrm{pH} 7.5$ for strains FF011L $\mathrm{L}^{\mathrm{T}}$ and $\mathrm{EC} 9^{\mathrm{T}}$ and $\mathrm{pH} 8.5$ for strains $\mathrm{K}^{22.7^{\mathrm{T}}}$ and HG15A2 ${ }^{\mathrm{T}}$ (Table 1), making all strains neutrophiles. However, when evaluating the results of the $\mathrm{pH}$ tolerance tests, we found that the strains modified the $\mathrm{pH}$ values within the buffered medium towards values between $\mathrm{pH} 7.0$ and 8.0 which rather suggests a $\mathrm{pH}$ optimum at $~ 7.5$. Usually, alterations of $\mathrm{pH}$ levels during bacterial growth are a known phenomenon caused by the release of acidic or basic compounds as metabolic end products [95]. In cases where $\mathrm{pH}$ values should not be adjusted by the culture, buffer concentration higher than the $10 \mathrm{mM}$ used here would be necessary.

All strains tested positive for cytochrome oxidase activity. The same was true for the determination of catalase activity. Fatty acid analyses revealed $C_{18: 1} \omega 9 \mathrm{c}$ as the major compound in strains $\mathrm{K}_{22.7^{\mathrm{T}}}$, $\mathrm{FF} 011 \mathrm{~L}^{\mathrm{T}}$, and $\mathrm{HG} 15 \mathrm{~A} 2^{\mathrm{T}}$, making up $42.5 \%, 55.1 \%$, and $34.8 \%$ of detected fatty acids, respectively, while $\mathrm{C}_{16: 0}$ was the second most abundant fatty acid. In strain $\mathrm{EC}^{\mathrm{T}}$, it was the other way around, the major fatty acid component being $\mathrm{C}_{16: 0}$ with $37.3 \%$. A detailed overview of fatty acid contents of strains described in this study and related planctomycetal type strains is provided in Supplementary Table S4.

Substrate utilization was determined with the MicroLog 96 substrate spectrum plates for Gram-negative bacteria. Two replicate plates were analyzed for each strain, and data were visualized as a heatmap dendrogram (Figure 4). However, analysis of the substrate spectra raised the question of the replicability of results. While the qualitative statement concerning whether a substrate could in principle be used by a strain is feasible, an inference of the quantitative 'strength' of utilization was not possible (Figure 4). This problem has been described before for bacteria of other phyla [96], but also for Planctomycetes [97]. A possible explanation for the deviant results might be the use of different cultures for inoculation of the assays. It is possible that these cultures were at different developmental stages, even though inoculated from the same pre-culture, thereby featuring a different ratio of planktonic and attached-living cells that could likely influence the substrate preferences of the culture [98]. 


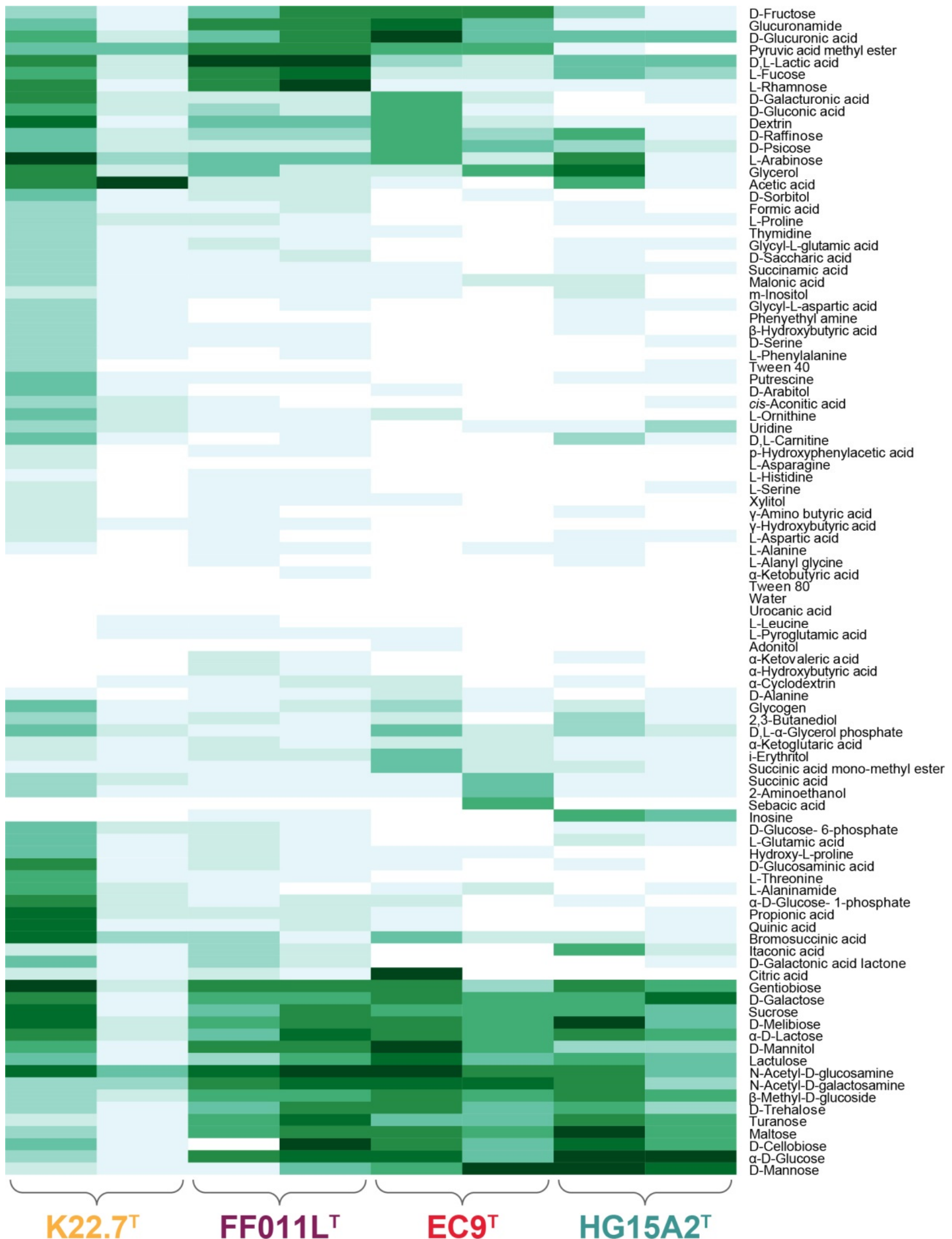

Figure 4. Heatmap of substrate utilization patterns of strains $\mathrm{K} 22.7^{\mathrm{T}}, \mathrm{FF} 011 \mathrm{~L}^{\mathrm{T}}, \mathrm{EC} 9^{\mathrm{T}}$ and $\mathrm{HG} 15 \mathrm{~A} 2^{\mathrm{T}}$. Two biological replicates were performed using the MicroLog GN2 substrate plates. Color scale shows substrate usage in percent utilization (white: $0 \%$, dark green: $100 \%$ ). 
We found that strains FF011L $\mathrm{L}^{\mathrm{T}}$ and $\mathrm{K} 22.7^{\mathrm{T}}$ were able to utilize 89 and 88 of all 95 tested substrates, respectively, while strains $\mathrm{HG} 15 \mathrm{~A} 2^{\mathrm{T}}$ and $\mathrm{EC} 9^{\mathrm{T}}$ only were capable to consume 75 and 59 substrates, respectively (Figure 4). The substrate spectra did not show any correlation with the genome size or growth rate. Interestingly, and in contrast to the two other strains, $\mathrm{EC} 9^{\mathrm{T}}$ and $\mathrm{HG} 15 \mathrm{~A} 2^{\mathrm{T}}$ failed to utilize most of the tested amino acids. Additionally, strain $\mathrm{EC}^{\mathrm{T}}$ was less prone to the utilization of various carboxylic acids. In total, 34 out of 95 substrates were used by all strains in all replicates: 2-aminoethanol, bromosuccinic acid, D-fructose, D-galactose, D-glucuronic acid, D-mannitol, D-mannose, D-melibiose, D-psicose, D-raffinose, D-trehalose, D,L-lactic acid, D,L- $\alpha$-glycerol phosphate, dextrin, gentiobiose, glucuronamide, glycerol, glycogen, i-erythritol, L-arabinose, L-fucose, L-rhamnose, lactulose, maltose, mono-methyl-succinate, $N$-acetyl-D-galactos amine, $N$-acetyl-D-glucosamine, succinic acid, sucrose, turanose, $\alpha$-D-glucose, $\alpha$-D-lactose, $\alpha$-ketoglutaric acid, and $\beta$ methyl-D-glucoside. The only substrates not used by any strain were Tween 80 and urocanic acid. As expected, this range of substrates being accepted by all strains includes D-glucose and $N$-acetyl-D-glucosamine, the latter being frequently used to selectively enrich planctomycetes from environmental samples [43]. Additionally, all four strains were able to utilize D-mannitol, a sugar alcohol frequently found in the cell walls of brown algae, especially Laminaria species, in which it can account for up to $25 \%$ of the dry weight in algal fronds [99]. The strains were also capable of metabolizing sugars such as glucose, mannose, galactose, and arabinose, which are monomers present in hydrolysates of brown macroalgae, like Laminaria and Fucus, and in species of the green seaweed Ulva [100,101]. Other frequent algal sugars like fucose and rhamnose are also consumed by all strains, implying that planctomycetes can feed on algal material, maybe even upon active degradation [25].

To further investigate if the novel strains were indeed able to grow on algal particles, we determined the fate of strain $\mathrm{K} 22.7^{\mathrm{T}}$ when providing algal powder of a Fucus species as sole carbon and nitrogen source. The combination of the strain and the powder was chosen on purpose as strain $\mathrm{K} 22.7^{\mathrm{T}}$ was originally isolated from a Fucus biofilm. Growth of the strain on the algal particles was documented by scanning electron microscopy (SEM) (Figure 5), which shows a tight attachment of the planctomycetal cells to the particles, consistent with their suspected capability to feed on algal matter. The ability of Planctomycetes to degrade complex polysaccharides, including chondroitin sulfate and laminarin, has been previously reported [97] and species of the genus Rhodopirellula were found to encode more than 100 sulfatases in their genomes, possibly enabling the degradation of a variety of different substrates of high chemical complexity [38]. This finding is especially interesting in light of the above mentioned hypothesis of planctomycetes being active degraders of their hosts [25].

\subsection{Morphology and Cell Biology}

For investigation of the cellular morphology and cell size of strains $\mathrm{K} 22.7^{\mathrm{T}}, \mathrm{FF} 011 \mathrm{~L}^{\mathrm{T}}$, $\mathrm{EC}^{\mathrm{T}}$, and HG15A2 ${ }^{\mathrm{T}}$ (Figure 6), we performed light, scanning, and transmission electron microscopy (Figure 7). Strain $\mathrm{K} 22.7^{\mathrm{T}}$ was $2.5 \pm 0.4 \mu \mathrm{m}$ in length and $1.4 \pm 0.3 \mu \mathrm{m}$ in width. Strain FF011L $\mathrm{L}^{\mathrm{T}}$ was smaller, measuring $2.0 \pm 0.3 \mu \mathrm{m}$ in length and $1.0 \pm 0.2 \mu \mathrm{m}$ in width. With its elongated cell bodies, cells of strain EC9 ${ }^{\mathrm{T}}$ measured $2.4 \pm 0.3 \mu \mathrm{m}$ in length and $1.2 \pm 0.2 \mu \mathrm{m}$ in width. The smallest of the novel strains was HG15A2 ${ }^{\mathrm{T}}$, measuring $1.8 \pm 0.2$ in length and $1.3 \pm 0.2 \mu \mathrm{m}$ in width (Figure 6, Table 1). This smallest of the four strains showed an egg-shaped morphology. It divides by polar budding (Figure 7D). Cells of strain HG15A2 ${ }^{\mathrm{T}}$ occurred as single cells or aggregates of 3-10 cells (Figure 7D-g,h). 

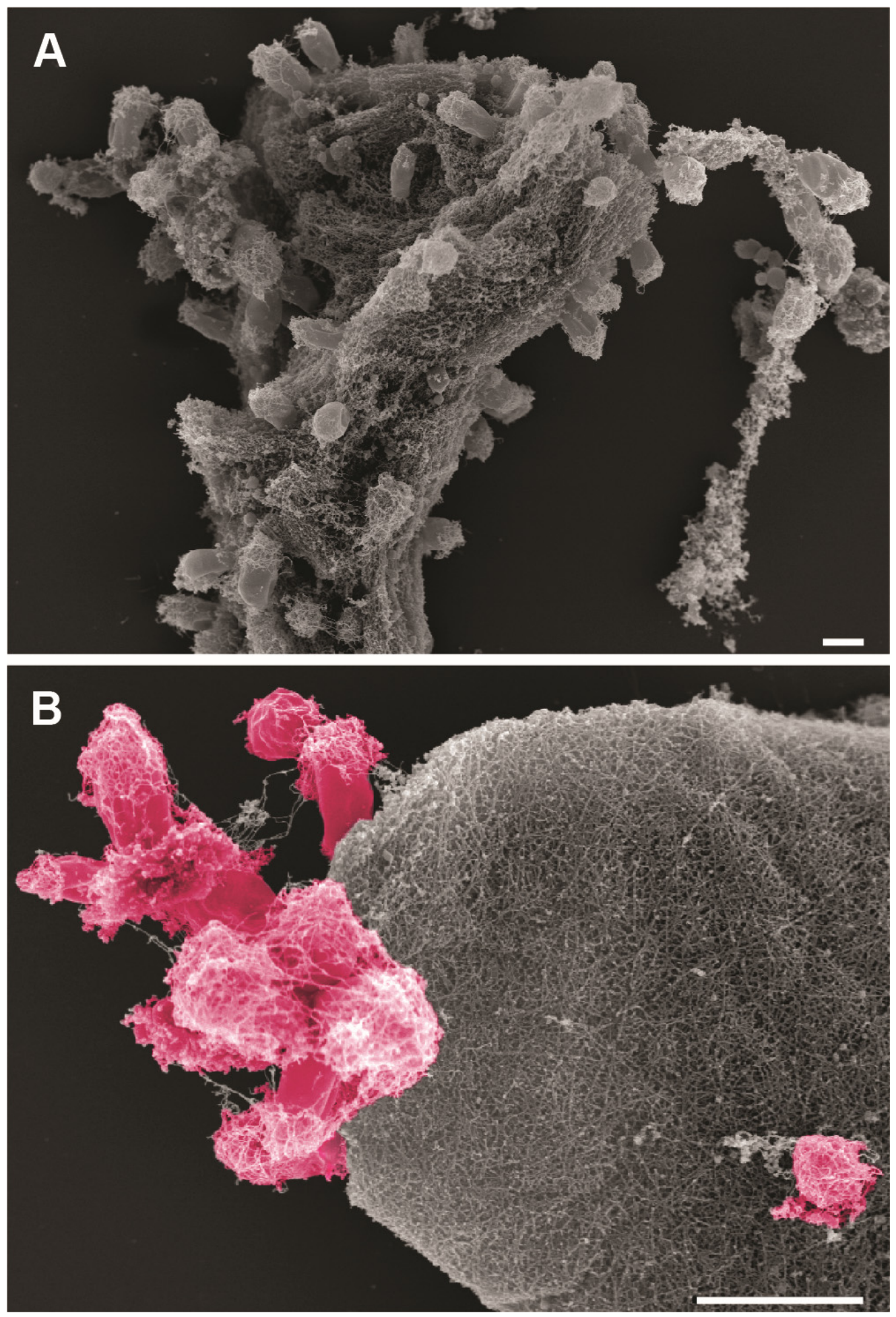

Figure 5. Attachment of strain $\mathrm{K} 22.7^{\mathrm{T}}$ to algal particles. Strain $\mathrm{K} 22.7^{\mathrm{T}}$ was cultivated in AMS medium containing Fucus sp. particles as sole carbon and nitrogen source. Attachment of $\mathrm{K} 22.7^{\mathrm{T}}$ cells to algal particles was visualized by SEM (A,B) and the false color image (B) shows bacterial cells (hot pink) attached to an algal particle in higher magnification. No budding cells were observed in the culture at day 21 of incubation, but pili-like fibers covered the pole caps of individual cells. Scale bars $1 \mu \mathrm{m}$. 


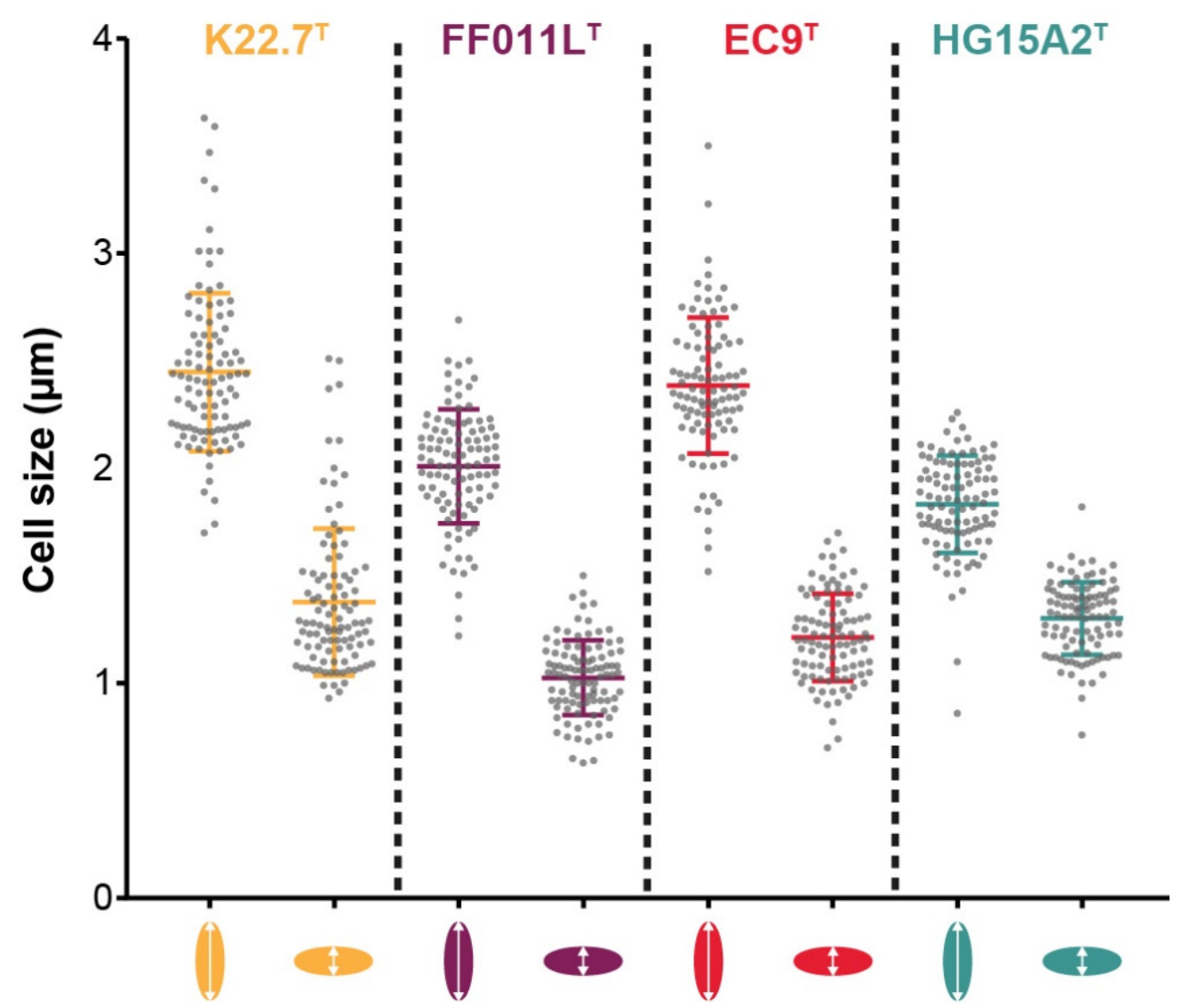

Figure 6. Cell sizes of the isolated planctomycetal strains $\mathrm{K} 22.7^{\mathrm{T}}, \mathrm{FF} 011 \mathrm{~L}^{\mathrm{T}}, \mathrm{EC}{ }^{\mathrm{T}}$ and $\mathrm{HG} 15 \mathrm{~A} 2^{\mathrm{T}}$. Average cell size of all strains was investigated by light microscopy and under phase-contrast illumination. Cell size was determined by measuring 100 individual cells per strain. Each dot represents one measurement and median and standard deviation values are indicated.

Several planctomycetal strains show a dimorphic lifecycle involving sessile mother cells and flagellated daughter cells. Attachment or aggregate formation in liquid cultures often leads to a higher viscosity when cultures reached the stationary phase, while high mobility of smaller swimmer cells turned out to be a characteristic feature during the exponential phase. SEM imaging revealed the existence of a thick extracellular matrix compound, in which the cells were embedded. This compound also interconnected single cells through thick appendages (up to $500 \mathrm{~nm}$ ) that could be very short but could also reach several micrometers in length (Figure 7D-e-h). In line with the higher viscosity of stationary cultures, the connective extracellular compound was present in higher quantities in late stationary phase cultures in comparison to exponential cultures. Transmission electron microscopy (TEM) of thin sections revealed a double membrane system, compartmentalizing the cells in a Planctomycetes-typical periplasmic space with several invaginations and a cytoplasmic space which contained the condensed nucleoid (Figure 7D-c,d). In addition, some cells showed intracytoplasmic parallel-running membrane stacks with individual lengths from $300 \mathrm{~nm}$ to $1.5 \mu \mathrm{m}$ (Figure 7D-c,d, white asterisks). Similar structures were detected in other planctomycetal species before, but no specific role or function was suggested [102,103]. The anammox (anaerobic ammonia oxidation) planctomycete Candidatus Kuenenia stuttgartiensis was described to harbor these tubule-like structures in its supplementary compartment, the anammoxosome [104]. 

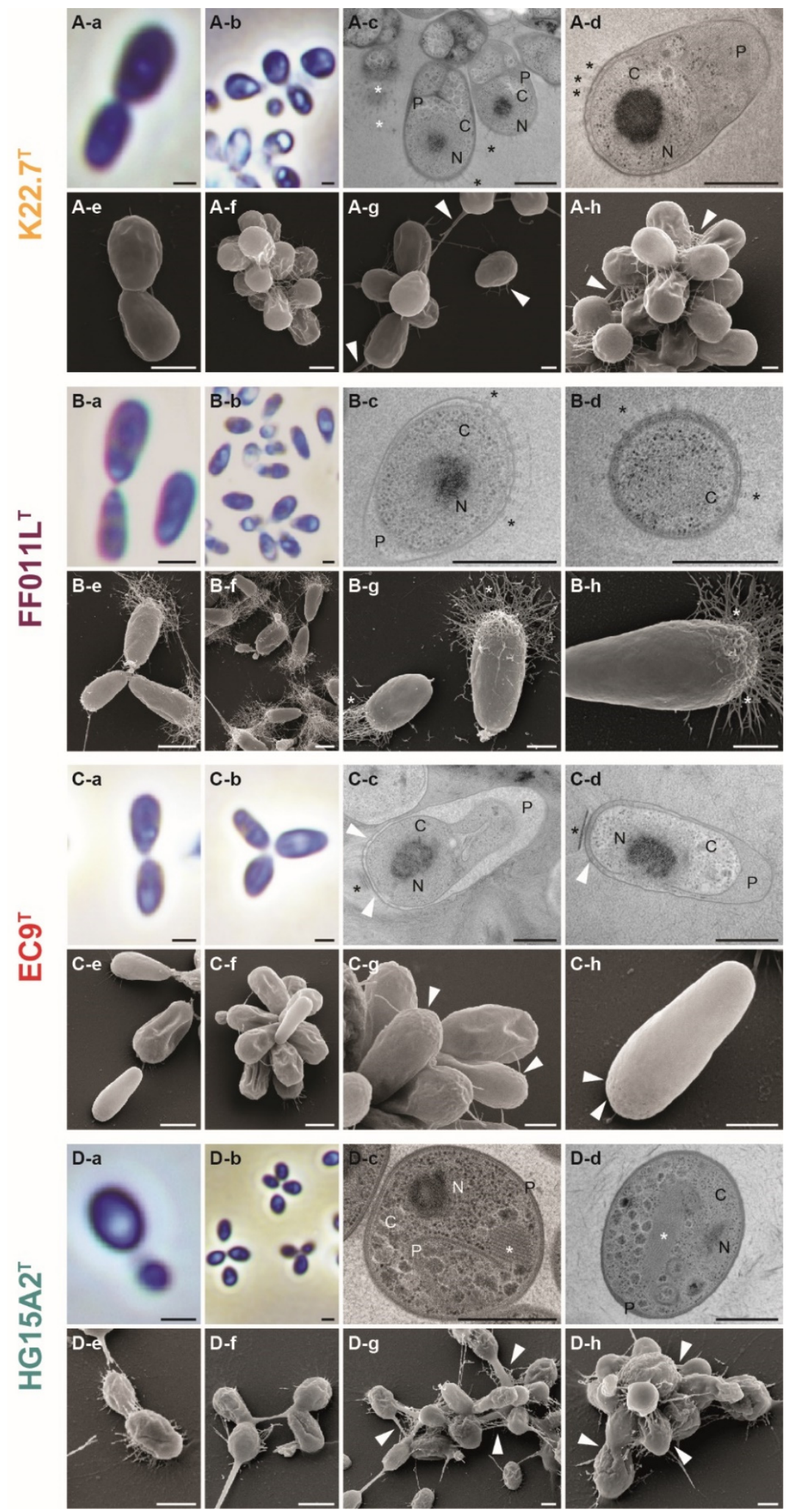

Figure 7. Morphology of strains K22.7 ${ }^{\mathrm{T}}$ (A), FF011L $\mathrm{L}^{\mathrm{T}}$ (B), EC9 ${ }^{\mathrm{T}}$ (C) and HG15A2 ${ }^{\mathrm{T}}$ (D). Phase contrast light microscopy $(\mathbf{a}, \mathbf{b})$, transmission electron microscopy of thin sections $(\mathbf{c}, \mathbf{d})$ and scanning electron microscopy (e-h) of all strains. (C) Cytoplasm; (N) condensed nucleoid; (P) periplasm. Explanations to asterisks and arrowheads are given in the text. Scale bars are $1 \mu \mathrm{m}(\mathbf{a}-\mathbf{c}, \mathbf{f})$ and $500 \mathrm{~nm}(\mathbf{c}, \mathbf{d}, \mathbf{g}, \mathbf{h})$.

The observed microstructures were hypothesized to be related to cytoskeletal elements or displaying a higher organization of an abundant protein which assembles into the 
observed meta-structure [104,105]. A recent study indeed suggested that these stacked microstructures are indeed a higher organization of an abundant protein as they specifically co-localized with antibodies against a nitrite oxidoreductase (NXR) [106]. The function of the microstructures in aerobic planctomycetes however remains elusive.

Phase contrast imaging revealed a typical planctomycetal cell shape for strain $\mathrm{K} 22.7^{\mathrm{T}}$, for which cells are slightly elongated with a pear-like morphology (Figure 7A). Cells reproduce by polar budding (Figure 7A-a). No motility or chain formation were observed (Figure 7A-b). SEM imaging of cells grown in standard M1H NAG ASW medium displayed a smooth cell surface with no crateriform structures visible (Figure 7A-e), indicating the embedding in a dense extracellular matrix. Cells form aggregates and small rosettes consisting of 3-6 cells and usually connected at the narrower pole (Figure 7A-a,d) by the release of sparse fibers from the matrix (Figure 7A-g,h, white arrowheads). The extracellular compound was also visible in liquid cultures, in which cells formed dense biofilms on glass surfaces when incubated under constant agitation. Notably, the strain showed a different morphology when cultured with algal powder as carbon and nitrogen source (Figure 5B,C).

Cells of strain FF011L $\mathrm{L}^{\mathrm{T}}$ had a pear-like cell shape with one pole wider than the other (Figure 7B) and the cells divide by polar budding (Figure 7B-a). No aggregate formation in liquid culture (Figure 7B-b) and no motile cells were observed during phase contrast microscopy. SEM imaging revealed a network of fiber-like structures at the wider cell pole of strain FF011L $\mathrm{L}^{\mathrm{T}}$ (Figure 7B-e-h) and the existence of a holdfast structure at the narrower pole (Figure 7B-e,g). The two features allowed the cells to connect closely via the narrower pole, while the fiber-like structures assembled the cells into loose aggregates, thereby allowing the formation of rosettes of up to 10 cells. The tight mesh of fibers was not only present in large, mature cells, but also in smaller cells (Figure 7B-g). TEM imaging of thin sections of strain FF011L $\mathrm{L}^{\mathrm{T}}$ showed cells with a condensed nucleoid and often enlarged periplasmic space (Figure 7B-c,d). The rim of the wider pole of the cells was seamed with tubule- or fiber-like structures, which stretch through the outer most membrane into the periplasmic space (Figure 7B-c,d, black asterisks). The top-down visible in Figure 7B-d indicated that the structures are distributed evenly around the cap of the wider cell pole.

Strain EC9 ${ }^{\mathrm{T}}$ displayed a distinctly slim pear-shaped morphology with one pole being wider than the other (Figure 7C). Cells formed large aggregates and rosettes with large and small cells attached to each other at the narrower pole (Figure $7 \mathrm{C}-\mathrm{a}, \mathrm{b}, \mathrm{f})$. Cells divide by polar budding (Figure $7 \mathrm{C}-\mathrm{f}$ ). Motility was not observed at the analyzed time points. TEM imaging showed cells with a condensed nucleoid as well as a partially invaginated periplasmic space and a cytoplasmic space of varying size parted by two double membranes (Figure 7C-c,d). In addition, many cells showed an extracellularly attached, stacked structure which seemed to be tangential to the wider cell pole (Figure 7C-c,d, black asterisk). However, no similar structure could be observed in SEM images. Furthermore, cells of strain $\mathrm{EC} 9^{\mathrm{T}}$ showed crateriform structures, evenly distributed at the cap of the wider cell pole (Figure $7 \mathrm{C}-\mathrm{g}, \mathrm{h}$, white arrowheads) that were also visible in cells investigated by TEM imaging (Figure 7C-c,d, white arrowheads). Not unlike strain FF011L ${ }^{\mathrm{T}}$, dense fiber-like appendages were formed on the broad pole, while the narrower pole mediated the attachment to the algal particles.

For strain $\mathrm{K} 22.7^{\mathrm{T}}$, TEM images revealed a similar cellular structure as strains EC9 ${ }^{\mathrm{T}}$ and FF011 $\mathrm{L}^{\mathrm{T}}$, showing a condensed nucleoid, partially enlarged periplasm and a cytoplasm with ribosomes (Figure 7A-c,d). The strain also displayed tubule- or fiber-like structures which locate through the outermost membrane into the periplasmic space (Figure 7A-c,d, black asterisks) seen before in strain FF011 $\mathrm{L}^{\mathrm{T}}$. These structures potentially correspond to the fibers observed by SEM in standard medium for strain FF011L $\mathrm{L}^{\mathrm{T}}$ and algal medium for strain $\mathrm{K} 22.7^{\mathrm{T}}$ as they are also located at the wider cell pole. Similar structures were previously described in related planctomycetes [102], but their organization or function was not further investigated. However, the elucidation of the architecture of type IV pili in Thermus thermophilus showed that the pili apparatus possesses structural elements very similar to those seen in our strains $\mathrm{K} 22.7^{\mathrm{T}}$ and FF011L $\mathrm{L}^{\mathrm{T}}$ [107]. Likewise, the localization of 
the type IV pilus was identical, spanning through the periplasmic space to the outside of the cell. While type IV pili are associated with a wide range of functions, such as twitching motility, DNA uptake and microcolony formation [108], another role has been recently suggested for similar structures observed on the surface of the distant relative Planctopirus limnophila, a member of the order Planctomycetales [41]. It has been observed that the appendages seem to protrude from the crateriform structures and that they are capable to bind complex branched carbohydrates, implying a role of the appendages in nutrient uptake [41]. The formation of appendages by strain K22.7 $7^{\mathrm{T}}$ in an algal medium rich in suspended macromolecules, but a lack of their formation when fewer complex sugars are provided, is consistent with this hypothesis [41,109].

\subsection{Phylogenetic Inference and Analysis of Genome-Encoded Features}

The construction of a genome-based tree from a multilocus sequence analysis (MLSA) as well as a 16S rRNA gene sequence-based phylogenetic tree confirmed the placement of the four novel strains in the order Pirellulales (see Sections 3.6-3.9, Figure 8 and Supple-

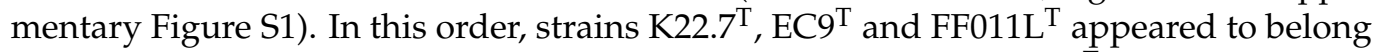
to different genera of the family Pirellulaceae, whereas strain $\mathrm{HG} 15 \mathrm{~A} 2^{\mathrm{T}}$ was identified as member of the family Lacipirellulaceae.

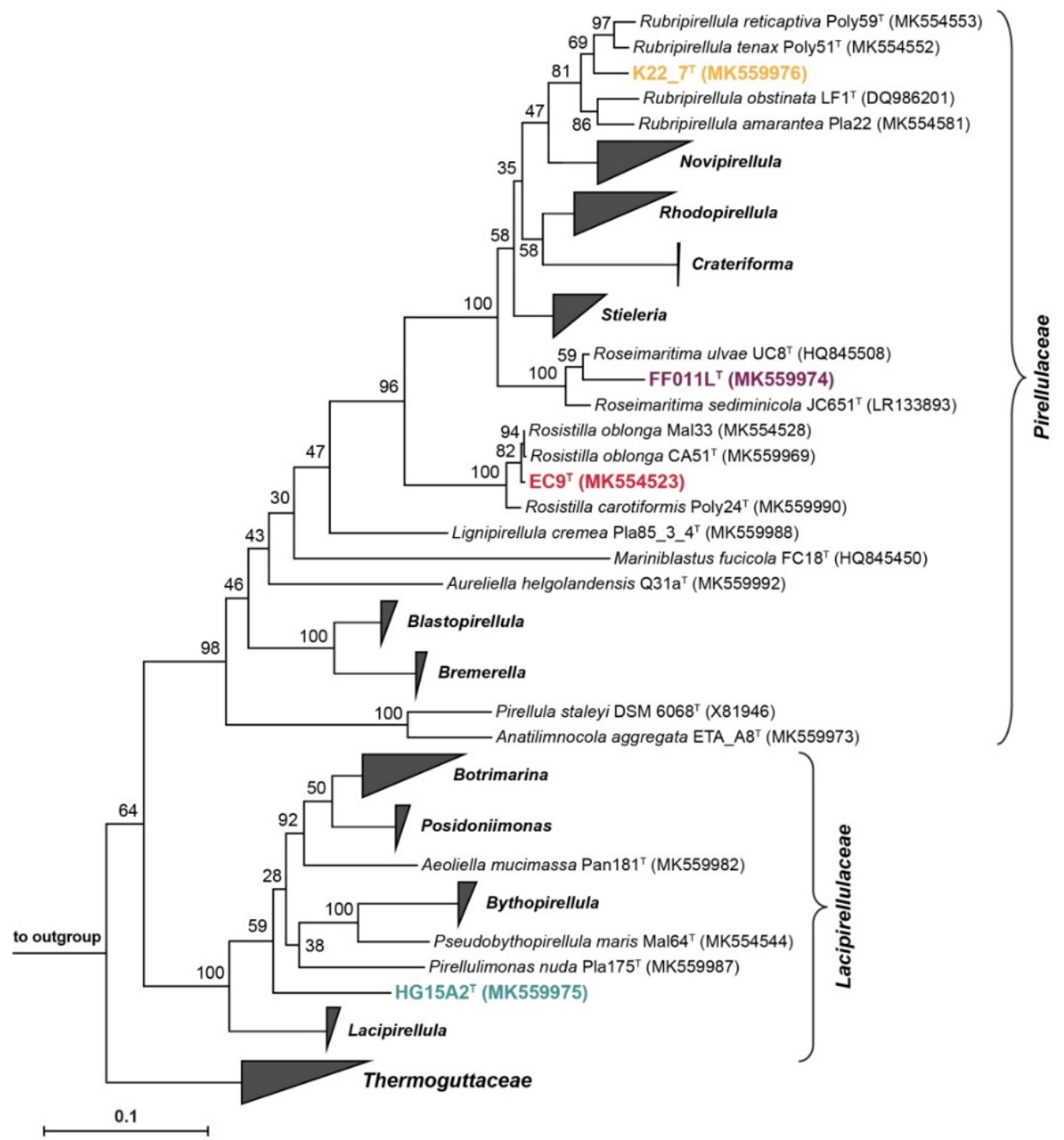

Figure 8. Phylogeny of the novel strains within the order Pirellulales. For the 16S rRNA analysis, maximum likelihood estimation-gained bootstrap values after 1000 re-samplings are given at the nodes in percent. The outgroup consists of three 16S rRNA genes from the family Planctomycetales. 


\subsection{Strain $\mathrm{K} 22.7^{T}$ and the Genus Rubripirellula}

In both phylogenetic trees (Figure 8 and Supplementary Figure S1), strain K22. $7^{\mathrm{T}}$ clustered within the genus Rubripirellula $[29,61]$. The assumption that strain $\mathrm{K} 22.7^{\mathrm{T}}$ belongs to this genus was confirmed by average amino identities (AAI) and the percentage of conserved proteins (POCP) given that all values were distinctly above the proposed genus thresholds of 60-80\% [110] and 50\% [84], respectively (Supplementary Figure S2). Average nucleotide identities (ANI) distinctly below the species threshold of $95 \%$ [111] in turn suggest that strain $\mathrm{K} 22.7^{\mathrm{T}}$ does not belong to one of the previously described strains of the genus. This notion is supported by rрoB sequence identity values below the proposed species threshold of 95.5\% [80] and above the newly defined genus threshold of 75.5-78.0\% [61]. Eventually, 16S rRNA gene sequence identities between $96.0 \%$ and $97.2 \%$ also suggest the classification of strain $\mathrm{K} 22.7^{\mathrm{T}}$ as a representative of a new species within the genus Rubripirellula as these values fall below the species threshold of $98.7 \%$, but above the genus threshold of $94.5 \%$ (Supplementary Figure S2) [112]. The genome sizes for the described strains within the genus Rubripirellula vary between 6.95 and $8.54 \mathrm{Mb}$ with strain $\mathrm{K} 22.7^{\mathrm{T}}$ having the largest genome and the only one being completely closed (Supplementary Table S5). With 57.3\%, the strain also has the highest DNA G+C content of the genus Rubripirellula. The strain features the most genes with a size $>15 \mathrm{~kb}$, the so-called giant genes, and the highest number of transposable elements. In contrast to the other members of the genus, strain $\mathrm{K} 22.7^{\mathrm{T}}$ harbors two $16 \mathrm{~S}$ rRNA gene copies and two 23S /5S rRNA operons. The strain has the fewest tRNAs. Due to its large genome, strain K22.7 ${ }^{\mathrm{T}}$ harbors the highest number of 6512 total genes, of which 6461 are protein-coding. The strain also has the highest count of 4320 unspecified hypothetical proteins. While the five strains of the current genus share a core genome of 1966 genes with a high density of annotated genes, 2540 of strain $\mathrm{K} 22.7^{\mathrm{T}}$ 's genes were not found in any of the other genus members (Figure 9A).

\subsection{Strain FF011L $L^{T}$ and the Genus Roseimaritima}

Upon inspection of the 16S rRNA gene sequence- and the MLSA-based phylogenetic trees (Figure 8 and Supplementary Figure S3), it became evident that strain FF011L ${ }^{\mathrm{T}}$ clusters within the genus Roseimaritima $[29,65]$. Its phylogenetic position including assignment to the genus Roseimaritima is supported by both, the POCP as well as the AAI values, found to be above the respective genus thresholds of $50 \%$ and $60-80 \%$, respectively $[84,110]$ (Supplementary Figure S3). It was however not clear from the trees which one of the two already described strains of the genus is the current closest relative of the novel strain and whether strain FF011 $\mathrm{L}^{\mathrm{T}}$ also constitutes a novel species. The ANI value distinctly hinted to the interpretation as novel species, a finding that is additionally supported by the rpoB gene sequence identity (Supplementary Figure S3) and the 16 rRNA gene sequence identity (Supplementary Figure S3) as all values for these two parameters were above the genus, but below the species threshold. This said, strain FF011L ${ }^{\mathrm{T}}$ can be clearly delineated from the two described species in the genus and should thus be regarded as the member of a novel species within the genus.

In direct comparison of strain FF011L $\mathrm{L}^{\mathrm{T}}$ and the two already described species of the genus Roseimaritima, R. ulvae, and R. sediminicola, the strains' genome sizes fell between 6.25 and $8.21 \mathrm{Mb}$ (Supplementary Table S6). The genomes cover a DNA G+C content range from 54.5 to $62.4 \%$, with strain FF011 $\mathrm{L}^{\mathrm{T}}$ having the lowest $\mathrm{G}+\mathrm{C}$ content. Automated gene annotation of the genome of strain FF011L $\mathrm{L}^{\mathrm{T}}$ yielded 5533 predicted genes, of which 5482 are annotated as proteins. While these values put the strain between its two described relatives, strain FF011 $\mathrm{L}^{\mathrm{T}}$ encodes these features with the highest count per $\mathrm{Mb}$. The three genomes share 2507 genes, whereas strain $\mathrm{FF} 011 \mathrm{~L}^{\mathrm{T}}$ also harbors 2300 genes that are not shared within the genus (Figure 9B). Strain FF011L $\mathrm{L}^{\mathrm{T}}$ does not have many giant genes, but 41 transposable elements. As the only member of its genus, strain $F F 011 \mathrm{~L}^{\mathrm{T}}$ features two $16 \mathrm{~S}$ rRNA genes and two 23S/5S rRNA operons, but has the fewest tRNA genes. 

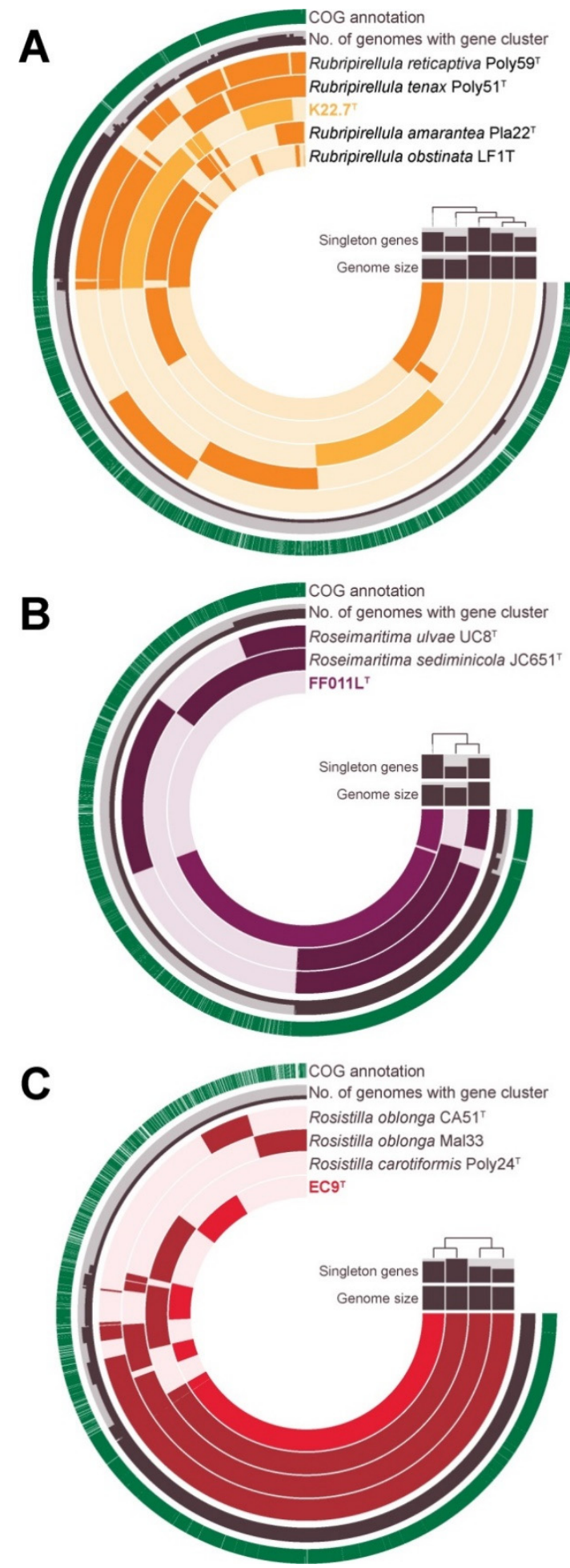

Figure 9. Pan genome of the novel strains in the context of their genera. Each open circle represents the pan genome of all strains but is colored darker when the gene is present in the respective genome. The trees reflect on the relatedness of the strains based on the absence/presence of genes. The outer circles show the number of genomes in which a gene is present and if it has a COG annotation (dark grey) thereby relaying information on how good the genes are annotatable. (A): Strain $\mathrm{K} 22.7^{\mathrm{T}}$ and the genus Rubripirellula. (B): Strain FF011L $\mathrm{L}^{\mathrm{T}}$ and the genus Roseimaritima. (C): Strain EC9 ${ }^{\mathrm{T}}$ and the genus Rosistilla. Strain HG15A2 ${ }^{\mathrm{T}}$ was omitted since it is currently the sole member of the novel genus Adhaeretor. 


\subsection{Strain $E C 9^{T}$ and the Genus Rosistilla}

When reviewing 16S rRNA gene sequence- as well as MLSA-based phylogeny of strain $\mathrm{EC} 9^{\mathrm{T}}$ and its close neighbors (Figure 8 and Supplementary Figure S1), it became apparent that the novel strain belongs to the only recently described genus Rosistilla, which comprises $R$. oblonga and $R$. carotiformis [31]. The assessment that these species and strain EC9 ${ }^{\mathrm{T}}$ belong to the same genus is confirmed by AAI and POCP values distinctly above the genus thresholds (Supplementary Figure S4). With an ANI value $<90 \%$, an $r p o B$ gene identity of $92.3 \%$, and a $16 \mathrm{~S}$ rRNA gene sequence identity of $98.6 \%$ (Figure $9 \mathrm{C}$ and Supplementary Figure S4), it is also conclusive that strain EC9 ${ }^{\mathrm{T}}$ does not belong to the species Rosistilla carotiformis. The identity values between strain EC9 ${ }^{\mathrm{T}}$ and the Rosistilla oblonga type strain CA51 ${ }^{\mathrm{T}}$ are however less clear: while the ANI value of $90.3 \%$ is clearly below the accepted species threshold of $95 \%$ [111], the $r p o B$ gene identity of $97.3 \%$ and the $16 \mathrm{~S}$ rRNA gene sequence identity of $99.6 \%$ both fall above the proposed species thresholds of $95.5 \%$ and $98.7 \%$, respectively [80,112]. In case of the phylum Planctomycetes, it has been shown before that strains often belong to different species according to ANI analysis despite 16S rRNA sequence identities $>99 \%[36,109,113]$. We therefore assigned strain EC ${ }^{\mathrm{T}}$ to a separate species based on the ANI value being distinctly below the species threshold, especially as this result was supported by the evaluation of the Rosistilla genomes: while the genomes of the Rosistilla oblonga strains have a very similar DNA G+C content of $58.1 \%$ and $58.2 \%$, strain $\mathrm{EC}^{\mathrm{T}}$ has a lower DNA G+C content of $57.9 \%$. The genomes reach a size between 7.25 and $7.51 \mathrm{Mb}$ (Supplementary Table S7), thereby carrying 5298 to 5576 predicted genes, 4012 of which are shared between all four strains (Figure 9C). The two Rosistilla oblonga strains $\mathrm{CA} 51^{\mathrm{T}}$ and Mal33 exclusively shared 256 further genes, while $\mathrm{EC}^{\mathrm{T}}$ and CA51 ${ }^{\mathrm{T}}$ only shared $58, \mathrm{EC} 9^{\mathrm{T}}$ and Mal33 shared 57 , and $\mathrm{EC} 9^{\mathrm{T}},{ }^{\mathrm{N}}$ Mal33, and CA51 ${ }^{\mathrm{T}}$ shared 155 genes. Strain EC $9^{\mathrm{T}}$ and Rosistilla carotiformis Poly $24^{\mathrm{T}}$, however, shared 264 genes, thereby indicating a genetic distance between strain $\mathrm{EC} 9^{\mathrm{T}}$ and the species Rosistilla oblonga.

\subsection{Strain $H G 15 A 2^{T}$ and the Family Lacipirellulaceae}

Both, MLSA- as well as $16 \mathrm{~S}$ rRNA sequence-based phylogeny (Figure 8 and Supplementary S1) suggested that strain $\mathrm{HG} 15 \mathrm{~A} 2^{\mathrm{T}}$ is a member of the only recently proposed and then expanded planctomycetal family Lacipirellulaceae $[42,63,114]$. The placement as a new genus is supported by AAI and POCP values found to fall below (in a single case slightly above) the genus thresholds of $60-80 \%$ and $50 \%$, respectively $[84,110]$ (Supplementary Figure S5). In addition, the determined $r p o B$ gene identity values are in line with our conclusion to delineate the strain from the known genera in the family Lacipirellulaceae. All 16S rRNA gene sequence identities are below the genus threshold of $94.5 \%$, but above the family threshold of $86.5 \%$ [112]. Within the Lacipirellulaceae, the genome of strain HG15A2 ${ }^{\mathrm{T}}$ is a rather typical representative member of this taxon (Supplementary Table S8).

\subsection{Genome-Based Analysis of Metabolic Features of the Novel Isolates}

As all four novel isolates are aerobic heterotrophs, we expected to find genes encoding a canonical primary carbon metabolism. Nevertheless, since the central carbon metabolism of the class Planctomycetia has not been studied in detail, we analyzed the genomes of the isolates for the presence of genes encoding enzymes involved in glycolytic pathways and gluconeogenesis, the tricarboxylic acid (TCA) cycle and anaplerotic reactions such as the phosphoenolpyruvate-pyruvate-oxaloacetate node and the glyoxylate shunt. Although genes coding for most of the enzymes required for the activity of central metabolic pathways were identified, there were also some anomalies that might require additional attention in the future.

Strain $\mathrm{K} 22.7^{\mathrm{T}}$ harbors the entire set of genes coding for enzymes of glycolytic pathways. Next to the common Embden-Meyerhof-Parnas pathway, the alternative Entner-Doudoroff pathway as well as the pentose phosphate pathway appear to be functional. Strain K22.7 is currently the sole member of the genus Rubripirellula harboring the gene for a 2,3bisphosphoglycerate-dependent phosphoglycerate mutase (encoded by gpmA) in addition 
to the 2,3-bisphosphoglycerate-independent isoenzyme (encoded by gpmI) found in all current members of the genus. The strain encodes all enzymes of the TCA cycle, but lacks the glyoxylate shunt. The latter appears to be a common feature of members of the class Planctomycetia when considering that genes for the two involved enzymes, isocitrate lyase and malate synthase, have not been identified in any isolate belonging to this class [31]. Furthermore, all characterized strains of the genus Rubripirellula and strain K22.7 ${ }^{\mathrm{T}}$ probably lack the enzymatic activity required to convert fructose-1,6-bisphosphate into fructose-6phosphate during gluconeogenesis. This would imply that none of these strains is capable of de novo biosynthesis of monosaccharides, which in turn are essential for the biosynthesis of cell wall components, nucleic acids, and certain amino acids.

In the genome of strain $\mathrm{EC} 9^{\mathrm{T}}$ and its close relatives, the genes for all enzymes involved in the central carbon metabolism are present, except for the two above-mentioned enzymes of the glyoxylate shunt [31].

For strain FF011L $\mathrm{L}^{\mathrm{T}}$, the encoded genes suggest intact glycolytic pathways and a complete TCA cycle. The analysis also points towards an incomplete set of gluconeogenesis enzymes and the lack of the sucA gene coding for the E1 component of the 2-oxoglutarate dehydrogenase complex in several members of the family including strain HG15A2 ${ }^{\mathrm{T}}$. Nevertheless, the four novel isolates appear to have a central carbon metabolism similar to that of other heterotrophic bacteria.

Members of the phylum Planctomycetes have been suggested to be a promising source for the isolation of novel secondary metabolites with important bioactivities, e.g., antioxidative or antimicrobial properties $[39,40,97,115]$. To address this potential, we identified and analyzed biosynthetic gene clusters (BGCs) encoded by the novel isolates that might be of importance in that regard. The analysis yielded 4-7 putative BGCs relevant for secondary metabolite production in the four isolates and a correlation between genome size and the number of BCGs was found to some extent (Supplementary Table S9). The identified BGCs can be split into two groups: (I) clusters coding for enzymes involved in isoprenoid and terpenoid production and (II) clusters containing larger genes coding for modular multi-domain proteins belonging to the classes of polyketide synthases (PKSs) or non-ribosomal peptide synthetases (NRPSs). Clusters falling in group I encode early biosynthetic proteins of carotenoid- or hopanoid-forming pathways, e.g., phytoene and squalene synthases or polyprenyl synthetases and terpene cyclases [116,117]. The presence of such genes is in line with the presence of carotenoids in three out of the four isolates that show a pink to red pigmentation or the presence of hopanoids, which have also been found to be produced by planctomycetes $[118,119]$. Products obtained from PKS and NRPS proteins encoded in clusters of group II have a broad range of functions, e.g., as antibiotics, surfactants, secondary lipids, siderophores, etc. [120-122]. Strains $\mathrm{K}^{22.7^{\mathrm{T}}}, \mathrm{FF} 011 \mathrm{~L}^{\mathrm{T}}$, and EC9 ${ }^{\mathrm{T}}$ harbour four such clusters belonging to group II, whereas only two group II BCGs could be identified in strain $\mathrm{HG} 15 \mathrm{~A} 2^{\mathrm{T}}$, which has a considerably smaller genome compared to the other three strains.

The predicted BGCs only showed low similarity of $<10 \%$ to hits of the most recent version of antiSMASH. This indicates that the secondary metabolites produced by proteins encoded in these cluster, although having a similar function as known compounds, are likely structurally different from previously characterized molecules identified in bacteria and fungi [39].

\subsection{Conclusions}

As planctomycetes are known to often occur attached to algal surfaces, the aim of this study was to investigate the composition of the bacterial epiphytic community on different macroalgae. Despite the long generation times of Planctomycetes compared to other heterotrophic bacteria inhabiting such surfaces [94], we found that the phylum constitutes the dominant fraction of bacteria on Fucus sp. biofilms and also occurs on Ulva sp. and Laminaria sp. that were sampled in the North Sea. In order to gain more insight into the mechanisms by which those slow-growing bacteria colonize macroalgae in a competitive 
environment, four novel planctomycetal strains belonging to the order Pirellulales were brought into axenic culture and it was exemplarily shown for strain $\mathrm{K} 22.7^{\mathrm{T}}$ that such strains have the ability to grow on algal particles. Further experiments, including setups with living algal material, will be needed to investigate the true nature of planctomycetal biofilm formers and to solve the question whether their relationship with algae is mutually beneficial, opportunistic or simply parasitic.

Based on the results of our polyphasic analysis of four novel planctomycetal isolates that included chemotaxonomy, physiological features, morphology, cell biology, phylogenetic markers, and genome comparisons, we conclude that strain $\mathrm{K} 22.7^{\mathrm{T}}$ belongs to a novel species in the genus Rubripirellula, for which we propose the name Rubripirellula lacrimiformis. Furthermore, strain FF011L $\mathrm{L}^{\mathrm{T}}$ constitutes a novel species of the genus Roseimaritima with the proposed name Roseimaritima multifibrata and strain $\mathrm{EC}^{\mathrm{T}}$ is a member of a yet uncharacterized species of the genus Roseimaritima, for which we introduce the name Rosistilla ulvae. Finally, strain HG15A2 ${ }^{\mathrm{T}}$ constitutes a novel species of a novel genus within the family Lacipirellulaceae, for which the name Adhaeretor mobilis is proposed.

\section{Genus and Species Protologues}

\subsection{Description of Adhaeretor gen. nov.}

Adhaeretor (Ad.hae.re'tor. N.L. masc. n. Adhaeretor from L. v. adhaerere to stick, to cling; an adhering bacterium).

Cells are round rice grain-shaped to round and form multicellular rosettes and aggregates. Cells divide by polar budding, are motile during the exponential growth phase and do not form spores. Extracellular matrix and biofilm formation in liquid culture are observed during cultivation. Aerobic, mesophilic, and neutrophilic growth properties. The molar DNA G+C content is 55-56\%. The predominant cellular fatty acid of the type species is oleic acid $\left(\mathrm{C}_{18: 1} \omega 9 \mathrm{c}\right)$. The genus belongs to the phylum Planctomycetes, class Planctomycetia, order Pirellulales, family Lacipirellulaceae. The type species of the genus is Adhaeretor mobilis.

\subsection{Description of Adhaeretor mobilis sp. nov.}

Adhaeretor mobilis (mo'bi.lis. L. masc. adj. mobilis movable, mobile, showing motility; corresponding to the high motility of swimmer cells observed during exponential growth phase).

Adhaeretor mobilis exhibits the following properties in addition to those given for the genus: Colonies have a white to cream color and a smooth surface. Growth is preferred in presence of gellan gum compared to agar as solidifying agent. Cells are $1.8 \times 1.3 \mu \mathrm{m}$ in size and react positively for catalase and cytochrome oxidase activity. Growth of the type strain is observed over a temperature range from $12-28{ }^{\circ} \mathrm{C}$ with an optimum at $22{ }^{\circ} \mathrm{C}$. The optimal $\mathrm{pH}$ for growth is 8.5 while growth was also obtained from pH 5.5 to 10.0. Utilizes a variety of sugar substrates and carboxylic acids, including D-cellobiose, D-galactose, D-glucuronic acid, D-mannitol, D-mannose, D-melibiose, D-psicose, D-trehalose, D,L-lactic acid, gentiobiose, inosine, L-fucose, lactulose, maltose, $N$-acetyl-D-galactosamine, $N$-acetylD-glucosamine, sucrose, turanose, $\alpha$-D-glucose, $\alpha$-D-lactose, and $\beta$-methyl-D-glucoside. The G+C content of the DNA is $55.1 \%$. The type strain is HG15A2 ${ }^{\mathrm{T}}\left(=\mathrm{VKM} \mathrm{B}-3444^{\mathrm{T}}\right)$ and was isolated from the epiphytic biofilm community of brown algae of the genus Laminaria.

\subsection{Updated Description of Roseimaritima Bondoso et al. 2016}

Properties of the genus are as given previously [29], with the following amendment: Cells of species belonging to the genus are spherical, ovoid, or have a tear- or drop-like cell shape. 


\subsection{Description of Roseimaritima multifibrata sp. nov.}

Roseimaritima multifibrata (mul.ti.fi.bra'ta. L. masc. adj. multus much, many, numerous; L. fem. adj. fibrata fibrous; N.L. fem. adj. multifibrata corresponding to the numerous fibers of the cells).

Cells have an average size of $2.0 \times 1.0 \mu \mathrm{m}$ and an elongated tear shape. Cells form multicellular rosettes and aggregates. Motility and spore formation were not observed. Cells divide by polar budding. Extracellular matrix and biofilms are produced during cultivation in liquid culture. Cells form a holdfast structure and crateriform structures were observed at the cell poles. Fimbriae originate from one of the poles. Colonies are pink. Growth is aerobic, mesophilic, and neutrophilic. Growth of the type strain was observed over a temperature range of $12-30{ }^{\circ} \mathrm{C}$ with optimal growth at $26^{\circ} \mathrm{C}$. Optimum $\mathrm{pH}$ for growth is 7.5 while a $\mathrm{pH}$ in the range of 5.5 to 10.0 still allowed for growth. Cells have catalase and cytochrome oxidase activity. The major cellular fatty acid of the type species is $\mathrm{C}_{18: 1} \omega 9 \mathrm{c}$. A variety of sugar substrates and carboxylic acids are degraded: acetic acid, D-fructose, D-galactonic acid lactone, D-galactose, D-galacturonic acid, D-glucuronic acid, D-mannitol, D-melibiose, D-raffinose, D-trehalose, D,L-lactic acid, dextrin, gentiobiose, glucuronamide, L-arabinose, L-fucose, L-rhamnose, lactulose, maltose, methyl pyruvate, $N$-acetyl-D-galactosamine, $N$-acetyl-D-glucosamine, sucrose, turanose, $\alpha$-D-glucose, $\alpha$-Dlactose, and $\beta$-methyl-D-glucoside. The G+C content of the DNA is $54.5 \%$. The type strain is FF011L $\mathrm{L}^{\mathrm{T}}\left(=\mathrm{DSM} 29513^{\mathrm{T}}=\mathrm{LMG} 29016^{\mathrm{T}}\right)$ and was isolated from the epiphytic biofilm community of brown algae of the genus Laminaria.

\subsection{Description of Rosistilla ulvae sp. nov.}

Rosistilla ulvae (ul'vae. N.L. gen. n. ulvae of Ulva, the genus name of the sea lettuce host; corresponding to the origin of the strain).

The cell shape resembles elongated drops or tears. Cells have an average size of $2.4 \times 1.2 \mu \mathrm{m}$, which form multicellular rosettes and aggregates. Cells are motile and do not form spores. Division takes place by polar budding, with the daughter cell emerging from the bigger pole. Extracellular matrix and biofilm formation in liquid culture are observed during cultivation. Colonies are red and have a smooth surface. Cells show catalase and cytochrome oxidase activity. The major cellular fatty acid is $\mathrm{C}_{16: 0}$. The type strain grows aerobically over a temperature range of $10-33{ }^{\circ} \mathrm{C}$ with optimal growth at $30^{\circ} \mathrm{C}$. Optimal growth was observed at $\mathrm{pH}$ 8.0, while growth was also observed over a $\mathrm{pH}$ range from 5.5 to 9.5. Rosistilla ulvae utilizes a variety of sugar substrates and carboxylic acids, including D-cellobiose, D-fructose, D-galactose, D-glucuronic acid, D-mannitol, Dmannose, D-melibiose, D-psicose, D-raffinose, D-trehalose, D,L-lactic acid, gentiobiose, glucuronamide, glycerol, lactulose, maltose, methyl pyruvate, mono-methyl-succinate, $N$-acetyl-D-galactosamine, $N$-acetyl-D-glucosamine, sucrose, turanose, $\alpha$-D-glucose, $\alpha$-Dlactose, and $\beta$-methyl-D-glucoside. The G+C content of the DNA is $57.9 \%$. The type strain is EC9 ${ }^{\mathrm{T}}\left(=\mathrm{DSM} 29815^{\mathrm{T}}=\mathrm{LMG} 29013^{\mathrm{T}}\right)$ and was isolated from the epiphytic biofilm community of green algae of the genus Ulva.

\subsection{Description of Rubripirellula lacrimiformis $s p$. nov.}

Rubripirellula lacrimiformis (la.cri.mi.for'mis. L. fem. n. lacrima a tear; L. suff. adj. formis a form, a figure; N.L. fem. adj. lacrimiformis shaped like a tear; corresponding to the tear-shaped morphology of individual cells).

Cells have a tear-shaped morphology and a typical size of $2.5 \times 1.4 \mu \mathrm{m}$. Cells form multicellular rosettes and aggregates. Motility and spore formation were not observed. Cells divide by polar budding and are pear-shaped. Extracellular matrix and biofilms are produced during cultivation in liquid culture. Cells lack a stalk or holdfast structure and crateriform structures were not observed. Colonies are pink and have a smooth surface. Growth is aerobic, mesophilic and neutrophilic. Growth of the type strain was observed over a temperature range of $10-37^{\circ} \mathrm{C}$ with optimal growth at $26^{\circ} \mathrm{C}$. Optimum $\mathrm{pH}$ for growth is 8.5 while a $\mathrm{pH}$ in the range of $5.5-10.0$ still enabled growth. Cells have catalase 
and cytochrome oxidase activity. The major cellular fatty acid of the type species is $\mathrm{C}_{18: 1} \omega 9 \mathrm{c}$. A variety of sugar substrates and carboxylic acids are degraded: acetic acid, bromo succinic acid, D-galacturonic acid, D-psicose, D-raffinose, glucose-6-phosphate, L-arabinose, methyl pyruvate, $N$-acetyl-D-galactosamine, $N$-acetyl-D-glucosamine, succinic acid, and $\beta$-methylD-glucoside. The G+C content of the DNA is $57.3 \%$. The type strain is $\mathrm{K}_{2} 2.7^{\mathrm{T}}$ (=DSM $29813^{\mathrm{T}}=\mathrm{LMG} 29017^{\mathrm{T}}$ ) and was isolated from the epiphytic biofilm community of brown algae of the genus Fucus.

Supplementary Materials: The following are available online at https: / www.mdpi.com/article / 10.3390/microorganisms9071494/s1, Figure S1: Phylogeny of the order Pirellulales based on whole genome-based multilocus sequence analysis (MLSA), Figure S2: Different parameters used to assign strain $\mathrm{K} 22.7^{\mathrm{T}}$ to the genus Rubripirellula, Figure S3: Different parameters to attribute strain FF011L $\mathrm{L}^{\mathrm{T}}$ to the genus Roseimaritima. Figure S4. Different parameters to attribute strain $\mathrm{EC} \mathrm{9}^{\mathrm{T}}$ to the genus Rosistilla. Figure S5: Different parameters to attribute strain $\mathrm{HG}_{15 \mathrm{~A} 2}{ }^{\mathrm{T}}$ to the family Lacipirellulaceae. Table S1: Cultivation media used in this study, Table S2: Oligonucleotides for amplicon generation used in this study, Table S3: Input and output data of the 16S rRNA gene amplicon analysis. Table S4: Cellular fatty acid contents (\%) of the novel strains and corresponding closely related type strains, Table S5: Genome characteristics of strain $\mathrm{K} 22.7^{\mathrm{T}}$ and other members of the genus Rubripirellula, Table S6: Genome characteristics of strain FF011L $\mathrm{L}^{\mathrm{T}}$ and other members of the genus Roseimaritima, Table S7: Genome characteristics of strain $\mathrm{EC}^{\mathrm{T}}$ and other members of the genus Rosistilla, Table S8: Genome characteristics of strain HG15A2 ${ }^{\mathrm{T}}$ and other members of the family Lacipirellulaceae, Table S9: Secondary metabolite biosynthetic gene clusters determined by AntiSMASH.

Author Contributions: S.W. wrote the manuscript and performed the genome-based analyses. P.R. was involved in sampling and performed most of the wet lab experiments. N.K. analysed secondary metabolite-associated biosynthetic gene clusters and enzymes of the primary metabolism and contributed to data analysis and text preparation. M.J. cultivated the strains and supervised P.R., A.H. isolated the novel strains and performed the cultivations for determination of the temperature and $\mathrm{pH}$ optimum for growth. C.B., T.K., and M.R. performed the microscopic analyses. O.J. was involved in strain deposition and contributed to data analysis and preparation of figures. C.Q. and F.O.G. were involved in the analysis of the amplicon sequence data. J.V. performed the amplicon sequencing. A.-K.K. supervised J.V. and helped with sequencing of amplicons and genomes. C.J. supervised the study, led the sampling expedition, and contributed to text preparation. All authors contributed to the manuscript and approved the submitted version. All authors have read and agreed to the published version of the manuscript.

Funding: The study was financially support by the Deutsche Forschungsgemeinschaft grants JO 893/4-1, KA 4967/1-1 and KA 4967/3-1.

Institutional Review Board Statement: Not applicable.

Informed Consent Statement: Not applicable.

Acknowledgments: All primers were developed by Pia Kaul and Boyke Bunk (DSMZ, Braunschweig, Germany). The authors would like to thank Ina Schleicher for dedicated sample preparation in the microscopy facility. We thank Jörn Petersen (DSMZ) and the Biological Institute Helgoland for sampling support.

Conflicts of Interest: The authors have no conflict of interest to declare. All co-authors have seen and agree with the contents of the manuscript. The submission is original work and is not under review at any other journal.

\section{References}

1. Oberbeckmann, S.; Labrenz, M. Marine Microbial Assemblages on Microplastics: Diversity, Adaptation, and Role in Degradation. Ann. Rev. Mar. Sci. 2020, 12, 209-232. [CrossRef]

2. Procopio, L. The role of biofilms in the corrosion of steel in marine environments. World J. Microbiol. Biotechnol. 2019, 35, 73. [CrossRef] [PubMed]

3. Dang, H.; Lovell, C.R. Microbial Surface Colonization and Biofilm Development in Marine Environments. Microbiol. Mol. Biol. Rev. 2016, 80, 91-138. [CrossRef] [PubMed] 
4. Antunes, J.; Leao, P.; Vasconcelos, V. Marine biofilms: Diversity of communities and of chemical cues. Environ. Microbiol. Rep. 2019, 11, 287-305. [CrossRef] [PubMed]

5. Bengtsson, M.M.; Sjøtun, K.; Øvreås, L. Seasonal dynamics of bacterial biofilms on the kelp Laminaria hyperborea. Aquat. Microb. Ecol. 2010, 60, 71-83. [CrossRef]

6. Moss, J.A.; Nocker, A.; Lepo, J.E.; Snyder, R.A. Stability and change in estuarine biofilm bacterial community diversity. Appl. Environ. Microbiol. 2006, 72, 5679-5688. [CrossRef]

7. Zhang, W.; Wang, Y.; Lee, O.O.; Tian, R.; Cao, H.; Gao, Z.; Li, Y.; Yu, L.; Xu, Y.; Qian, P.Y. Adaptation of intertidal biofilm communities is driven by metal ion and oxidative stresses. Sci. Rep. 2013, 3, 3180. [CrossRef]

8. Juhmani, A.S.; Vezzi, A.; Wahsha, M.; Buosi, A.; Pascale, F.; Schiavon, R.; Sfriso, A. Diversity and Dynamics of Seaweed Associated Microbial Communities Inhabiting the Lagoon of Venice. Microorganisms 2020, 8, 1657. [CrossRef]

9. Lachnit, T.; Blümel, M.; Imhoff, J.F.; Wahl, M. Specific epibacterial communities on macroalgae: Phylogeny matters more than habitat. Aquatic Biol. 2009, 5, 181-186. [CrossRef]

10. Hengst, M.B.; Andrade, S.; Gonzalez, B.; Correa, J.A. Changes in epiphytic bacterial communities of intertidal seaweeds modulated by host, temporality, and copper enrichment. Microb. Ecol. 2010, 60, 282-290. [CrossRef]

11. Ramanan, R.; Kim, B.H.; Cho, D.H.; Oh, H.M.; Kim, H.S. Algae-bacteria interactions: Evolution, ecology and emerging applications. Biotechnol. Adv. 2016, 34, 14-29. [CrossRef]

12. Florez, J.Z.; Camus, C.; Hengst, M.B.; Buschmann, A.H. A Functional Perspective Analysis of Macroalgae and Epiphytic Bacterial Community Interaction. Front. Microbiol. 2017, 8, 2561. [CrossRef] [PubMed]

13. Friedrich, M.W. Bacterial Communities on Macroalgae. In Seaweed Biology—Novel Insights into Ecophysiology, Ecology and Utilization; Wiencke, C., Bischof, K., Eds.; Springer: Berlin/Heidelberg, Germany, 2012.

14. Hollants, J.; Leliaert, F.; De Clerck, O.; Willems, A. What we can learn from sushi: A review on seaweed-bacterial associations. FEMS Microbiol. Ecol. 2013, 83, 1-16. [CrossRef]

15. Li, J.; Wang, T.; Yu, S.; Bai, J.; Qin, S. Community characteristics and ecological roles of bacterial biofilms associated with various algal settlements on coastal reefs. J. Environ. Manag. 2019, 250, 109459. [CrossRef] [PubMed]

16. Lachnit, T.; Meske, D.; Wahl, M.; Harder, T.; Schmitz, R. Epibacterial community patterns on marine macroalgae are host-specific but temporally variable. Environ. Microbiol. 2011, 13, 655-665. [CrossRef] [PubMed]

17. Sanli, K.; Bengtsson-Palme, J.; Nilsson, R.H.; Kristiansson, E.; Alm Rosenblad, M.; Blanck, H.; Eriksson, K.M. Metagenomic sequencing of marine periphyton: Taxonomic and functional insights into biofilm communities. Front. Microbiol. $2015,6,1192$. [CrossRef]

18. Zhang, W.; Ding, W.; Li, Y.X.; Tam, C.; Bougouffa, S.; Wang, R.; Pei, B.; Chiang, H.; Leung, P.; Lu, Y.; et al. Marine biofilms constitute a bank of hidden microbial diversity and functional potential. Nat. Commun. 2019, 10, 517. [CrossRef] [PubMed]

19. Bondoso, J.; Godoy-Vitorino, F.; Balague, V.; Gasol, J.M.; Harder, J.; Lage, O.M. Epiphytic Planctomycetes communities associated with three main groups of macroalgae. FEMS Microbiol. Ecol. 2017, 93, 3. [CrossRef] [PubMed]

20. Bondoso, J.; Balague, V.; Gasol, J.M.; Lage, O.M. Community composition of the Planctomycetes associated with different macroalgae. FEMS Microbiol. Ecol. 2014, 88, 445-456. [CrossRef]

21. Bengtsson, M.M.; Øvreås, L. Planctomycetes dominate biofilms on surfaces of the kelp Laminaria hyperborea. BMC Microbiol. 2010, 10, 261. [CrossRef]

22. Lage, O.M.; Bondoso, J. Planctomycetes and macroalgae, a striking association. Front. Microbiol. 2014, 5, 267. [CrossRef]

23. Lage, O.M.; Bondoso, J. Planctomycetes diversity associated with macroalgae. FEMS Microbiol. Ecol. 2011, 78, 366-375. [CrossRef]

24. Fukunaga, Y.; Kurahashi, M.; Sakiyama, Y.; Ohuchi, M.; Yokota, A.; Harayama, S. Phycisphaera mikurensis gen. nov., sp. nov., isolated from a marine alga, and proposal of Phycisphaeraceae fam. nov., Phycisphaerales ord. nov. and Phycisphaerae classis nov. in the phylum Planctomycetes. J. Gen. Appl. Microbiol. 2009, 55, 267-275. [CrossRef]

25. Wiegand, S.; Jogler, M.; Jogler, C. On the maverick Planctomycetes. FEMS Microbiol. Rev. 2018, 42, 739-760. [CrossRef] [PubMed]

26. Yoon, J.; Jang, J.H.; Kasai, H. Algisphaera agarilytica gen. nov., sp. nov., a novel representative of the class Phycisphaerae within the phylum Planctomycetes isolated from a marine alga. Antonie Van Leeuwenhoek 2014, 105, 317-324. [CrossRef] [PubMed]

27. Vollmers, J.; Frentrup, M.; Rast, P.; Jogler, C.; Kaster, A.K. Untangling Genomes of Novel Planctomycetal and Verrucomicrobial Species from Monterey Bay Kelp Forest Metagenomes by Refined Binning. Front. Microbiol. 2017, 8, 472. [CrossRef] [PubMed]

28. Bondoso, J.; Albuquerque, L.; Lobo-da-Cunha, A.; da Costa, M.S.; Harder, J.; Lage, O.M. Rhodopirellula lusitana sp. nov. and Rhodopirellula rubra sp. nov., isolated from the surface of macroalgae. Syst. Appl. Microbiol. 2014, 37, 157-164. [CrossRef]

29. Bondoso, J.; Albuquerque, L.; Nobre, M.F.; Lobo-da-Cunha, A.; da Costa, M.S.; Lage, O.M. Roseimaritima ulvae gen. nov., sp. nov. and Rubripirellula obstinata gen. nov., sp. nov. two novel planctomycetes isolated from the epiphytic community of macroalgae. Syst. Appl. Microbiol. 2015, 38, 8-15. [CrossRef]

30. Lage, O.M.; Albuquerque, L.; Lobo-da Cunha, A.; da Costa, M.S. Mariniblastus fucicola gen. nov., sp. nov. a novel planctomycete associated with macroalgae. Int. J. Syst. Evol. Microbiol. 2017, 67, 1571-1576. [CrossRef]

31. Waqqas, M.; Salbreiter, M.; Kallscheuer, N.; Jogler, M.; Wiegand, S.; Heuer, A.; Rast, P.; Peeters, S.H.; Boedeker, C.; Jetten, M.S.M.; et al. Rosistilla oblonga gen. nov., sp. nov. and Rosistilla carotiformis sp. nov., isolated from biotic or abiotic surfaces in Northern Germany, Mallorca, Spain and California, USA. Antonie Van Leeuwenhoek 2020, 113, 1939-1952. [CrossRef]

32. Wiegand, S.; Jogler, M.; Boedeker, C.; Heuer, A.; Peeters, S.H.; Kallscheuer, N.; Jetten, M.S.M.; Kaster, A.-K.; Rohde, M.; Jogler, C. Updates to the recently introduced family Lacipirellulaceae in the phylum Planctomycetes: Isolation of strains belonging to the 
novel genera Aeoliella, Botrimarina, Pirellulimonas and Pseudobythopirellula and the novel species Bythopirellula polymerisocia and Posidoniimonas corsicana. Antonie Van Leeuwenhoek 2020, 113, 1979-1997. [PubMed]

33. Salbreiter, M.; Waqqas, M.; Jogler, M.; Kallscheuer, N.; Wiegand, S.; Peeters, S.H.; Heuer, A.; Jetten, M.S.M.; Boedeker, C.; Rast, P.; et al. Three Planctomycetes isolated from biotic surfaces in the Mediterranean Sea and the Pacific Ocean constitute the novel species Symmachiella dynata gen. nov., sp. nov. and Symmachiella macrocystis sp. nov. Antonie Van Leeuwenhoek 2020, 113, $1965-1977$. [CrossRef] [PubMed]

34. Boersma, A.S.; Kallscheuer, N.; Wiegand, S.; Rast, P.; Peeters, S.H.; Mesman, R.J.; Heuer, A.; Boedeker, C.; Jetten, M.S.M.; Rohde, M.; et al. Alienimonas californiensis gen. nov. sp. nov., a novel Planctomycete isolated from the kelp forest in Monterey Bay. Antonie Van Leeuwenhoek 2020, 113, 1751-1766. [CrossRef]

35. Rivas-Marin, E.; Wiegand, S.; Kallscheuer, N.; Jogler, M.; Peeters, S.H.; Heuer, A.; Jetten, M.S.M.; Boedeker, C.; Rohde, M.; Devos, D.P.; et al. Thalassoglobus polymorphus sp. nov., a novel Planctomycete isolated close to a public beach of Mallorca Island. Antonie Van Leeuwenhoek 2020, 113, 1915-1926. [CrossRef] [PubMed]

36. Jogler, C.; Wiegand, S.; Boedeker, C.; Heuer, A.; Peeters, S.H.; Jogler, M.; Jetten, M.S.M.; Rohde, M.; Kallscheuer, N. Tautonia plasticadhaerens sp. nov., a novel species in the family Isosphaeraceae isolated from an alga in a hydrothermal area of the Eolian Archipelago. Antonie Van Leeuwenhoek 2020, 113, 1889-1900. [CrossRef]

37. Wecker, P.; Klockow, C.; Ellrott, A.; Quast, C.; Langhammer, P.; Harder, J.; Glockner, F.O. Transcriptional response of the model planctomycete Rhodopirellula baltica SH1(T) to changing environmental conditions. BMC Genom. 2009, 10, 410. [CrossRef]

38. Wegner, C.E.; Richter-Heitmann, T.; Klindworth, A.; Klockow, C.; Richter, M.; Achstetter, T.; Glöckner, F.O.; Harder, J. Expression of sulfatases in Rhodopirellula baltica and the diversity of sulfatases in the genus Rhodopirellula. Mar. Genom. 2012, 9, 51-61. [CrossRef]

39. Wiegand, S.; Jogler, M.; Boedeker, C.; Pinto, D.; Vollmers, J.; Rivas-Marin, E.; Kohn, T.; Peeters, S.H.; Heuer, A.; Rast, P.; et al. Cultivation and functional characterization of 79 planctomycetes uncovers their unique biology. Nat. Microbiol. 2020, 5, 126-140. [CrossRef]

40. Kallscheuer, N.; Jeske, O.; Sandargo, B.; Boedeker, C.; Wiegand, S.; Bartling, P.; Jogler, M.; Rohde, M.; Petersen, J.; Medem, M.H.; et al. The planctomycete Stieleria maiorica Mal15 $5^{\mathrm{T}}$ employs stieleriacines to alter the species composition in marine biofilms. Commun. Biol. 2020, 3, 303. [CrossRef]

41. Boedeker, C.; Schuler, M.; Reintjes, G.; Jeske, O.; van Teeseling, M.C.; Jogler, M.; Rast, P.; Borchert, D.; Devos, D.P.; Kucklick, M.; et al. Determining the bacterial cell biology of Planctomycetes. Nat. Commun. 2017, 8, 14853. [CrossRef]

42. Kallscheuer, N.; Rast, P.; Jogler, M.; Wiegand, S.; Kohn, T.; Boedeker, C.; Jeske, O.; Heuer, A.; Quast, C.; Glöckner, F.-O.; et al Analysis of bacterial communities in a municipal duck pond during a phytoplankton bloom and isolation of Anatilimnocola aggregata gen. nov., sp. nov., Lacipirellula limnantheis sp. nov. and Urbifossiella limnaea gen. nov., sp. nov. belonging to the phylum Planctomycetes. Environ. Microbiol. 2021, 23, 1379-1396.

43. Lage, O.M.; Bondoso, J. Bringing Planctomycetes into pure culture. Front. Microbiol. 2012, 3, 405. [CrossRef]

44. Godinho, O.; Calisto, R.; Ovreas, L.; Quinteira, S.; Lage, O.M. Antibiotic susceptibility of marine Planctomycetes. Antonie Van Leeuwenhoek 2019, 112, 1273-1280. [CrossRef]

45. Sipkema, D.; Schippers, K.; Maalcke, W.J.; Yang, Y.; Salim, S.; Blanch, H.W. Multiple approaches to enhance the cultivability of bacteria associated with the marine sponge Haliclona (gellius) sp. Appl. Environ. Microbiol. 2011, 77, 2130-2140. [CrossRef] [PubMed]

46. Rast, P.; Glockner, I.; Boedeker, C.; Jeske, O.; Wiegand, S.; Reinhardt, R.; Schumann, P.; Rohde, M.; Spring, S.; Glockner, F.O.; et al. Three Novel Species with Peptidoglycan Cell Walls form the New Genus Lacunisphaera gen. nov. in the Family Opitutaceae of the Verrucomicrobial Subdivision 4. Front. Microbiol. 2017, 8, 202. [CrossRef] [PubMed]

47. Buddruhs, N.; Pradella, S.; Goker, M.; Pauker, O.; Pukall, R.; Sproer, C.; Schumann, P.; Petersen, J.; Brinkhoff, T. Molecular and phenotypic analyses reveal the non-identity of the Phaeobacter gallaeciensis type strain deposits CIP $105210^{\mathrm{T}}$ and DSM 17395 . Int. J. Syst. Evol. Microbiol. 2013, 63 Pt 11, 4340-4349. [CrossRef]

48. R: A Language Environment for Statistical Computing. Available online: https:/ / www.r-project.org/ (accessed on 6 November 2017).

49. Miller, L.T. Single derivatization method for routine analysis of bacterial whole-cell fatty acid methyl esters, including hydroxy acids. J. Clin. Microbiol. 1982, 16, 584-586. [CrossRef] [PubMed]

50. Kuykendall, L.D.; Roy, M.A.; apos Neill, J.J.; Devine, T.E. Fatty Acids, Antibiotic Resistance, and Deoxyribonucleic Acid Homology Groups of Bradyrhizobium japonicum. Int. J. Syst. Evol. Microbiol. 1988, 38, 358-361. [CrossRef]

51. Blanco, L.; Bernad, A.; Lazaro, J.M.; Martin, G.; Garmendia, C.; Salas, M. Highly efficient DNA synthesis by the phage phi 29 DNA polymerase. Symmetrical mode of DNA replication. J. Biol. Chem. 1989, 264, 8935-8940. [CrossRef]

52. Dean, F.B.; Hosono, S.; Fang, L.; Wu, X.; Faruqi, A.F.; Bray-Ward, P.; Sun, Z.; Zong, Q.; Du, Y.; Du, J.; et al. Comprehensive human genome amplification using multiple displacement amplification. Proc. Natl. Acad. Sci. USA 2002, 99, 5261-5266. [CrossRef] [PubMed]

53. Muyzer, G.; de Waal, E.C.; Uitterlinden, A.G. Profiling of complex microbial populations by denaturing gradient gel electrophoresis analysis of polymerase chain reaction-amplified genes coding for 16S rRNA. Appl. Environ. Microbiol. 1993, 59, 695-700. [CrossRef] [PubMed] 
54. Bartram, A.K.; Lynch, M.D.; Stearns, J.C.; Moreno-Hagelsieb, G.; Neufeld, J.D. Generation of multimillion-sequence 16S rRNA gene libraries from complex microbial communities by assembling paired-end illumina reads. Appl. Environ. Microbiol. 2011, 77, 3846-3852. [CrossRef] [PubMed]

55. Bolger, A.M.; Lohse, M.; Usadel, B. Trimmomatic: A flexible trimmer for Illumina sequence data. Bioinformatics 2014, 30, 2114-2120. [CrossRef] [PubMed]

56. Edgar, R.C.; Haas, B.J.; Clemente, J.C.; Quince, C.; Knight, R. UCHIME improves sensitivity and speed of chimera detection. Bioinformatics 2011, 27, 2194-2200. [CrossRef] [PubMed]

57. Quast, C.; Pruesse, E.; Yilmaz, P.; Gerken, J.; Schweer, T.; Yarza, P.; Peplies, J.; Glöckner, F.O. The SILVA ribosomal RNA gene database project: Improved data processing and web-based tools. Nucleic Acids Res. 2013, 41, D590-D596. [CrossRef]

58. Pruesse, E.; Peplies, J.; Glockner, F.O. SINA: Accurate high-throughput multiple sequence alignment of ribosomal RNA genes. Bioinformatics 2012, 28, 1823-1829. [CrossRef]

59. Weizhong, L.; Godzik, A. Cd-hit: A fast program for clustering and comparing large sets of protein or nucleotide sequences. Bioinformatics 2006, 22, 1658-1659.

60. Jogler, C.; Glöckner, F.O.; Kolter, R. Characterization of Planctomyces limnophilus and development of genetic tools for its manipulation establish it as a model species for the phylum Planctomycetes. Appl. Environ. Microbiol. 2011, 77, 5826-5829. [CrossRef]

61. Kallscheuer, N.; Jogler, M.; Wiegand, S.; Peeters, S.H.; Heuer, A.; Boedeker, C.; Jetten, M.S.M.; Rohde, M.; Jogler, C. Three novel Rubripirellula species isolated from plastic particles submerged in the Baltic Sea and the estuary of the river Warnow in northern Germany. Antonie Van Leeuwenhoek 2020, 113, 1767-1778. [CrossRef]

62. Sandargo, B.; Jeske, O.; Boedeker, C.; Wiegand, S.; Wennrich, J.-P.; Kallscheuer, N.; Jogler, M.; Rohde, M.; Jogler, C.; Surup, F. Stieleriacines, $N$-Acyl Dehydrotyrosines From the Marine Planctomycete Stieleria neptunia sp. nov. Front. Microbiol. 2020, $11,1408$. [CrossRef]

63. Dedysh, S.N.; Kulichevskaya, I.S.; Beletsky, A.V.; Ivanova, A.A.; Rijpstra, W.I.C.; Damste, J.S.S.; Mardanov, A.V.; Ravin, N.V. Lacipirellula parvula gen. nov., sp. nov., representing a lineage of planctomycetes widespread in low-oxygen habitats, description of the family Lacipirellulaceae fam. nov. and proposal of the orders Pirellulales ord. nov., Gemmatales ord. nov. and Isosphaerales ord. nov. Syst. Appl. Microbiol. 2020, 43, 126050.

64. Storesund, J.E.; Ovreas, L. Diversity of Planctomycetes in iron-hydroxide deposits from the Arctic Mid Ocean Ridge (AMOR) and description of Bythopirellula goksoyri gen. nov., sp. nov., a novel Planctomycete from deep sea iron-hydroxide deposits. Antonie Van Leeuwenhoek 2013, 104, 569-584. [CrossRef]

65. Kumar, D.; Gaurav, K.; Jagadeeshwari, U.; Deepshikha, G.; Ch, S. Roseimaritima sediminicola sp. nov., a new member of Planctomycetaceae isolated from Chilika lagoon. Int. J. Syst. Evol. Microbiol. 2020, 70, 2616-2623. [CrossRef] [PubMed]

66. Kallscheuer, N.; Wiegand, S.; Heuer, A.; Rensink, S.; Boersma, A.S.; Jogler, M.; Boedeker, C.; Peeters, S.H.; Rast, P.; Jetten, M.S.M.; et al. Blastopirellula retiformator sp. nov. isolated from the shallow-sea hydrothermal vent system close to Panarea Island. Antonie Van Leeuwenhoek 2020, 113, 1811-1822. [CrossRef] [PubMed]

67. Rensink, S.; Wiegand, S.; Kallscheuer, N.; Rast, P.; Peeters, S.H.; Heuer, A.; Boedeker, C.; Jetten, M.S.M.; Rohde, M.; Jogler, M.; et al. Description of the novel planctomycetal genus Bremerella, containing Bremerella volcania sp. nov., isolated from an active volcanic site, and reclassification of Blastopirellula cremea as Bremerella cremea comb. nov. Antonie Van Leeuwenhoek 2020, 113, $1823-1837$. [CrossRef]

68. Slobodkina, G.B.; Panteleeva, A.N.; Beskorovaynaya, D.A.; Bonch-Osmolovskaya, E.A.; Slobodkin, A.I. Thermostilla marina gen. nov., sp. nov., a thermophilic, facultatively anaerobic planctomycete isolated from a shallow submarine hydrothermal vent. Int. J. Syst. Evol. Microbiol. 2016, 66, 633-638. [CrossRef]

69. Slobodkina, G.B.; Kovaleva, O.L.; Miroshnichenko, M.L.; Slobodkin, A.I.; Kolganova, T.V.; Novikov, A.A.; van Heerden, E.; Bonch-Osmolovskaya, E.A. Thermogutta terrifontis gen. nov., sp. nov. and Thermogutta hypogea sp. nov., thermophilic anaerobic representatives of the phylum Planctomycetes. Int. J. Syst. Evol. Microbiol. 2015, 65 Pt 3, 760-765. [CrossRef]

70. Yoon, J.; Matsuo, Y.; Kasai, H.; Lee, M.-K. Phylogenetic and taxonomic analyses of Rhodopirellula caenicola sp. nov., a new marine Planctomycetes species isolated from Iron Sand. J. Phylogenetics Evol. Biol. 2014, 3, 2.

71. Richter, M.; Richter-Heitmann, T.; Klindworth, A.; Wegner, C.-E.; Frank, C.S.; Harder, J.; Glöckner, F.O. Permanent draft genomes of the Rhodopirellula maiorica strain SM1. Mar. Genom. 2014, 13, 19-20. [CrossRef] [PubMed]

72. Schlesner, H.; Rensmann, C.; Tindall, B.J.; Gade, D.; Rabus, R.; Pfeiffer, S.; Hirsch, P. Taxonomic heterogeneity within the Planctomycetales as derived by DNA-DNA hybridization, description of Rhodopirellula baltica gen. nov., sp. nov., transfer of Pirellula marina to the genus Blastopirellula gen. nov. as Blastopirellula marina comb. nov. and emended description of the genus Pirellula. Int. J. Syst. Evol. Microbiol. 2004, 54 Pt 5, 1567-1580.

73. Kumar, D.; Kumar, G.; Uppada, J.; Ahmed, S.; Sasikala, C.; Venkata Ramana, C. Descriptions of Roseiconus nitratireducens gen. nov. sp. nov. and Roseiconus lacunae sp. nov. Arch. Microbiol. 2020, 203, 741-754. [CrossRef] [PubMed]

74. Stamatakis, A. RAxML version 8: A tool for phylogenetic analysis and post-analysis of large phylogenies. Bioinformatics 2014, 30, 1312-1313. [CrossRef] [PubMed]

75. Lechner, M.; Findeiss, S.; Steiner, L.; Marz, M.; Stadler, P.F.; Prohaska, S.J. Proteinortho: Detection of (co-)orthologs in large-scale analysis. BMC Bioinform. 2011, 12, 124. [CrossRef] 
76. Edgar, R.C. MUSCLE: Multiple sequence alignment with high accuracy and high throughput. Nucleic Acids Res. 2004, 32, 1792-1797. [CrossRef] [PubMed]

77. Castresana, J. Selection of Conserved Blocks from Multiple Alignments for Their Use in Phylogenetic Analysis. Mol. Biol. Evol. 2000, 17, 540-552. [CrossRef] [PubMed]

78. Price, M.N.; Dehal, P.S.; Arkin, A.P. FastTree 2-Approximately Maximum-Likelihood Trees for Large Alignments. PLoS ONE 2010, 5, e9490. [CrossRef] [PubMed]

79. Letunic, I.; Bork, P. Interactive Tree Of Life (iTOL) v4: Recent updates and new developments. Nucleic Acids Res. 2019, 1, gkz239. [CrossRef]

80. Bondoso, J.; Harder, J.; Lage, O.M. rpoB gene as a novel molecular marker to infer phylogeny in Planctomycetales. Antonie Van Leeuwenhoek 2013, 104, 477-488. [CrossRef] [PubMed]

81. Sievers, F.; Wilm, A.; Dineen, D.; Gibson, T.J.; Karplus, K.; Li, W.; Lopez, R.; McWilliam, H.; Remmert, M.; Söding, J. Fast, scalable generation of high-quality protein multiple sequence alignments using Clustal Omega. Mol. Syst. Biol. 2011, 7, 539. [CrossRef]

82. Lee, I.; Ouk Kim, Y.; Park, S.C.; Chun, J. OrthoANI: An improved algorithm and software for calculating average nucleotide identity. Int. J. Syst. Evol. Microbiol. 2016, 66, 1100-1103. [CrossRef]

83. Rodriguez-R, L.M.; Konstantinidis, K.T. The enveomics collection: A toolbox for specialized analyses of microbial genomes and metagenomes. PeerJ Preprints 2016, 4, e:1900v1.

84. Qin, Q.L.; Xie, B.B.; Zhang, X.Y.; Chen, X.L.; Zhou, B.C.; Zhou, J.; Oren, A.; Zhang, Y.Z. A proposed genus boundary for the prokaryotes based on genomic insights. J. Bacteriol. 2014, 196, 2210-2215. [CrossRef] [PubMed]

85. Mitchell, A.L.; Attwood, T.K.; Babbitt, P.C.; Blum, M.; Bork, P.; Bridge, A.; Brown, S.D.; Chang, H.Y.; El-Gebali, S.; Fraser, M.I.; et al. InterPro in 2019: Improving coverage, classification and access to protein sequence annotations. Nucleic Acids Res. 2019, 47, D351-D360. [CrossRef] [PubMed]

86. UniProt, C. UniProt: A worldwide hub of protein knowledge. Nucleic Acids Res. 2019, 47, D506-D515.

87. Blin, K.; Shaw, S.; Steinke, K.; Villebro, R.; Ziemert, N.; Lee, S.Y.; Medema, M.H.; Weber, T. antiSMASH 5.0: Updates to the secondary metabolite genome mining pipeline. Nucleic Acids Res. 2019, 47, W81-W87. [CrossRef]

88. Eren, A.M.; Esen, O.C.; Quince, C.; Vineis, J.H.; Morrison, H.G.; Sogin, M.L.; Delmont, T.O. Anvi'o: An advanced analysis and visualization platform for 'omics data. PeerJ 2015, 3, e1319. [CrossRef]

89. Delmont, T.O.; Eren, A.M. Linking pangenomes and metagenomes: The Prochlorococcus metapangenome. PeerJ 2018, 6, e4320. [CrossRef]

90. Spring, S.; Bunk, B.; Sproer, C.; Schumann, P.; Rohde, M.; Tindall, B.J.; Klenk, H.P. Characterization of the first cultured representative of Verrucomicrobia subdivision 5 indicates the proposal of a novel phylum. ISME J. 2016, 10, 2801-2816. [CrossRef]

91. Castelle, C.J.; Brown, C.T.; Anantharaman, K.; Probst, A.J.; Huang, R.H.; Banfield, J.F. Biosynthetic capacity, metabolic variety and unusual biology in the CPR and DPANN radiations. Nat. Rev. Microbiol. 2018, 16, 629-645. [CrossRef]

92. Brown, C.T.; Hug, L.A.; Thomas, B.C.; Sharon, I.; Castelle, C.J.; Singh, A.; Wilkins, M.J.; Wrighton, K.C.; Williams, K.H.; Banfield, J.F. Unusual biology across a group comprising more than 15\% of domain Bacteria. Nature 2015, 523, 208-211. [CrossRef]

93. Lawes, J.C.; Neilan, B.A.; Brown, M.V.; Clark, G.F.; Johnston, E.L. Elevated nutrients change bacterial community composition and connectivity: High throughput sequencing of young marine biofilms. Biofouling 2016, 32, 57-69. [CrossRef] [PubMed]

94. Dogs, M.; Wemheuer, B.; Wolter, L.; Bergen, N.; Daniel, R.; Simon, M.; Brinkhoff, T. Rhodobacteraceae on the marine brown alga Fucus spiralis are abundant and show physiological adaptation to an epiphytic lifestyle. Syst. Appl. Microbiol. 2017, 40, 370-382. [CrossRef] [PubMed]

95. Sánchez-Clemente, R.; Igeño, M.I.; Población, A.G.; Guijo, M.I.; Merchán, F.; Blasco, R. Study of pH changes in media during bacterial growth of several environmental strains. Multidiscip. Digit. Publ. Inst. Proc. 2018, 2, 1297. [CrossRef]

96. Verniere, C.; Pruvost, O.; Civerolo, E.L.; Gambin, O.; Jacquemoud-Collet, J.P.; Luisetti, J. Evaluation of the Biolog Substrate Utilization System To Identify and Assess Metabolic Variation among Strains of Xanthomonas campestris pv. Citri. Appl. Environ. Microbiol. 1993, 59, 243-249. [CrossRef]

97. Jeske, O.; Jogler, M.; Petersen, J.; Sikorski, J.; Jogler, C. From genome mining to phenotypic microarrays: Planctomycetes as source for novel bioactive molecules. Antonie Van Leeuwenhoek 2013, 104, 551-567. [CrossRef]

98. Costerton, J.W.; Lewandowski, Z.; Caldwell, D.E.; Korber, D.R.; Lappin-Scott, H.M. Microbial biofilms. Annu. Rev. Microbiol. 1995, 49, 711-745. [CrossRef]

99. Kraan, S. Algal Polysaccharides, Novel Applications and Outlook. In Carbohydrates_Comprehensive Studies on Glycobiology and Glycotechnology; IntechOpen Limited: London, UK, 2012; pp. 489-524.

100. Pengzhan, Y.; Quanbin, Z.; Ning, L.; Zuhong, X.; Yanmei, W.; Zhi'en, L. Polysaccharides from Ulva pertusa (Chlorophyta) and preliminary studies on their antihyperlipidemia activity. J. Appl. Phycol. 2003, 15, 21-27. [CrossRef]

101. Stiger-Pouvreau, V.; Bourgougnon, N.; Deslandes, E. Chapter 8 - Carbohydrates From Seaweeds. In Seaweed in Health and Disease Prevention; Fleurence, J., Levine, I., Eds.; Elsevier: Amsterdam, The Netherlands, 2016.

102. Lage, O.M.; Bondoso, J.; Lobo-da-Cunha, A. Insights into the ultrastructural morphology of novel Planctomycetes. Antonie Van Leeuwenhoek 2013, 104, 467-476. [CrossRef]

103. Schubert, T.; Kallscheuer, N.; Wiegand, S.; Boedeker, C.; Peeters, S.H.; Jogler, M.; Heuer, A.; Jetten, M.S.M.; Rohde, M.; Jogler, C. Calycomorphotria hydatis gen. nov., sp. nov., a novel species in the family Planctomycetaceae with conspicuous subcellular structures. Antonie Van Leeuwenhoek 2020, 113, 1877-1887. [CrossRef] 
104. van Niftrik, L.A.; Fuerst, J.A.; Sinninghe Damste, J.S.; Kuenen, J.G.; Jetten, M.S.; Strous, M. The anammoxosome: An intracytoplasmic compartment in anammox bacteria. FEMS Microbiol. Lett. 2004, 233, 7-13. [CrossRef]

105. van Niftrik, L. Cell biology of unique anammox bacteria that contain an energy conserving prokaryotic organelle. Antonie Van Leeuwenhoek 2013, 104, 489-497. [CrossRef]

106. de Almeida, N.M.; Neumann, S.; Mesman, R.J.; Ferousi, C.; Keltjens, J.T.; Jetten, M.S.; Kartal, B.; van Niftrik, L. Immunogold Localization of Key Metabolic Enzymes in the Anammoxosome and on the Tubule-Like Structures of Kuenenia stuttgartiensis. J. Bacteriol. 2015, 197, 2432-2441. [CrossRef]

107. Gold, V.A.; Salzer, R.; Averhoff, B.; Kuhlbrandt, W. Structure of a type IV pilus machinery in the open and closed state. Elife 2015, 4, e07380. [CrossRef] [PubMed]

108. Craig, L.; Forest, K.T.; Maier, B. Type IV pili: Dynamics, biophysics and functional consequences. Nat. Rev. Microbiol. 2019, 17, 429-440. [CrossRef]

109. Kohn, T.; Wiegand, S.; Boedeker, C.; Rast, P.; Heuer, A.; Jetten, M.S.M.; Schuler, M.; Becker, S.; Rohde, C.; Muller, R.W.; et al. Planctopirus ephydatiae, a novel Planctomycete isolated from a freshwater sponge. Syst. Appl. Microbiol. 2020, 43, 126022. [CrossRef] [PubMed]

110. Luo, C.; Rodriguez, R.L.; Konstantinidis, K.T. MyTaxa: An advanced taxonomic classifier for genomic and metagenomic sequences. Nucleic Acids Res. 2014, 42, e73. [CrossRef] [PubMed]

111. Kim, M.; Oh, H.S.; Park, S.C.; Chun, J. Towards a taxonomic coherence between average nucleotide identity and 16S rRNA gene sequence similarity for species demarcation of prokaryotes. Int. J. Syst. Evol. Microbiol. 2014, 64 Pt 2, 346-351. [CrossRef]

112. Yarza, P.; Yilmaz, P.; Pruesse, E.; Glöckner, F.O.; Ludwig, W.; Schleifer, K.H.; Whitman, W.B.; Euzeby, J.; Amann, R.; Rossello-Mora, R. Uniting the classification of cultured and uncultured bacteria and archaea using $16 \mathrm{~S}$ rRNA gene sequences. Nat. Rev. Microbiol. 2014, 12, 635-645. [CrossRef]

113. Yadav, S.; Vaddavalli, R.; Siripuram, S.; Eedara, R.V.V.; Yadav, S.; Rabishankar, O.; Lodha, T.; Chintalapati, S.; Chintalapati, V. Planctopirus hydrillae sp. nov., an antibiotic producing Planctomycete isolated from the aquatic plant Hydrilla and its whole genome shotgun sequence analysis. J. Antibiot. 2018, 71, 575-583. [CrossRef]

114. Kallscheuer, N.; Jogler, M.; Wiegand, S.; Peeters, S.H.; Heuer, A.; Boedeker, C.; Jetten, M.S.M.; Rohde, M.; Jogler, C. Rubinisphaera italica sp. nov. isolated from a hydrothermal area in the Tyrrhenian Sea close to the volcanic island Panarea. Antonie Van Leeuwenhoek 2020, 113, 1727-1736. [CrossRef] [PubMed]

115. Panter, F.; Garcia, R.; Thewes, A.; Zaburannyi, N.; Bunk, B.; Overmann, J.; Gutierrez, M.V.; Krug, D.; Müller, R. Production of a Dibrominated Aromatic Secondary Metabolite by a Planctomycete Implies Complex Interaction with a Macroalgal Host. ACS Chem. Biol. 2019, 14, 2713-2719. [CrossRef]

116. Kallscheuer, N.; Moreira, C.; Airs, R.; Llewellyn, C.A.; Wiegand, S.; Jogler, C.; Lage, O.M. Pink- and orange-pigmented Planctomycetes produce saproxanthin-type carotenoids including a rare $\mathrm{C}_{45}$ carotenoid. Environ. Microbiol. Rep. 2019, 11, 741-748. [PubMed]

117. Santana-Molina, C.; Rivas-Marin, E.; Rojas, A.M.; Devos, D.P. Origin and Evolution of Polycyclic Triterpene Synthesis. Mol. Biol. Evol. 2020, 37, 1925-1941. [CrossRef] [PubMed]

118. Damsté, J.S.S.; Rijpstra, W.I.C.; Schouten, S.; Fuerst, J.A.; Jetten, M.S.; Strous, M. The occurrence of hopanoids in planctomycetes: Implications for the sedimentary biomarker record. Org. Geochem. 2004, 35, 561-566. [CrossRef]

119. Rivas-Marin, E.; Stettner, S.; Gottshall, E.Y.; Santana-Molina, C.; Helling, M.; Basile, F.; Ward, N.L.; Devos, D.P. Essentiality of sterol synthesis genes in the planctomycete bacterium Gemmata obscuriglobus. Nat. Commun. 2019, 10, 2916. [CrossRef]

120. Quadri, L.E. Assembly of aryl-capped siderophores by modular peptide synthetases and polyketide synthases. Mol. Microbiol. 2000, 37, 1-12. [CrossRef]

121. Chen, M.; Wang, G.; Dai, S.; Xie, L.; Li, X. Polyketide antibiotics produced by polyketide synthase in streptomyces-A review. Acta Microbiol. Sin. 2009, 49, 1555-1563.

122. Li, H.; Tanikawa, T.; Sato, Y.; Nakagawa, Y.; Matsuyama, T. Serratia marcescens gene required for surfactant serrawettin W1 production encodes putative aminolipid synthetase belonging to nonribosomal peptide synthetase family. Microbiol. Immunol. 2005, 49, 303-310. [CrossRef] 